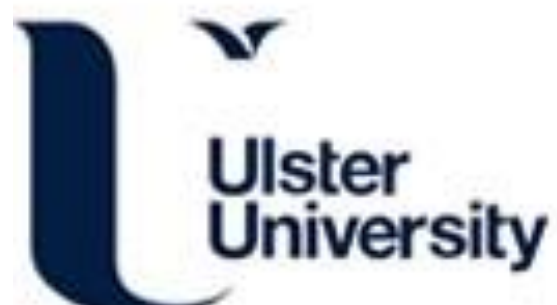

\section{On the CFD modelling of hydrogen dispersion at low-Reynolds number release in closed facility}

Giannissi, S. G., Tolias, I. C., Melideo, D., Baraldi, D., Shentsov, V., Makarov, DV., Molkov, V., \& Venetsanos, A. G. (2020). On the CFD modelling of hydrogen dispersion at low-Reynolds number release in closed facility. International Journal of Hydrogen Energy. https://doi.org/10.1016/j.ijhydene.2020.09.078

Link to publication record in Ulster University Research Portal

\section{Published in:}

International Journal of Hydrogen Energy

\section{Publication Status:}

Published online: 10/10/2020

DOI:

10.1016/j.ijhydene.2020.09.078

\section{Document Version}

Author Accepted version

\section{General rights}

Copyright for the publications made accessible via Ulster University's Research Portal is retained by the author(s) and / or other copyright owners and it is a condition of accessing these publications that users recognise and abide by the legal requirements associated with these rights.

\section{Take down policy}

The Research Portal is Ulster University's institutional repository that provides access to Ulster's research outputs. Every effort has been made to ensure that content in the Research Portal does not infringe any person's rights, or applicable UK laws. If you discover content in the Research Portal that you believe breaches copyright or violates any law, please contact pure-support@ulster.ac.uk. 


\section{ON THE CFD MODELLING OF HYDROGEN DISPERSION AT LOW-REYNOLDS NUMBER RELEASE IN CLOSED FACILITY}

\section{Introduction}

Hydrogen has been attracting a growing global interest as an energy carrier that could play a role in contributing to solve issues like climate change and as a result its use is expected to grow in the near future. Since 2016 hydrogen powered vehicles are publicly available in Japan, Korea and USA (like the Toyota Mirai, the Hyundai Nexo, and the Honda Clarity Fuel Cell) and other major car manufacturers have plan to start to produce hydrogen cars in the near future. Among other applications, hydrogen technologies are also considered for electricity production and as an energy storage solution for the energy supply chain. However, its release brings up safety concerns due to its wide range of flammability limits $(4 \%-75 \% \mathrm{v} / \mathrm{v})$ and due to the fact that a possible ignition may lead to slow or fast deflagrations, or even detonations under certain conditions.

In this context, it is necessary to perform safety analyses which show that the risk of hydrogen technologies can be comparable to that of more conventional technologies. The risks related to flammable buoyant gas release and dispersion should be investigated, in order to assess, prevent and mitigate the consequences of accidental hydrogen leaks. The study of gas dispersion can be conducted with the help of both experiments and simulations. Computational Fluid Dynamics (CFD) modelling has been widely used successfully in the past as a predicting tool and in order to assist the understanding of the relevant physical phenomena [1],[2],[3]. It can support hazardous/risk assessment [4],[5] and provide useful recommendations for safety measures [6]. 
However, in order to exploit the broad range of CFD capabilities, the appropriate modelling strategy should be followed to achieve accurate results [7].

Several CFD benchmarking studies ([8], [9], [10], [11], [12]) have been conducted in the past. However, in some of these studies the computational results were obtained without having followed accurately Best Practice Guidelines (BPG) for CFD, e.g. without performing all the appropriate sensitivity studies, in order to minimize the numerical effects. For instance, in [8] it is mentioned that not every partner conducted grid independence study and in some cases, time step was set to allow finishing calculations within logical time and thus suffered from low precision. Moreover, different grid types (hexahedral, tetrahedral and hybrid) were used without investigating their effect on the results [11].

For all the above, the first aim of the current study is to demonstrate the use of BPG that have been developed [13] for hydrogen safety CFD simulations. These BPG focus on the practical needs of engineers and aim to deal with the fact that several different users can produce different results for the same problem, using the same models or even CFD code [14], as it is exhibited in some of the works referenced above. Following these BPG, several sensitivity studies (grid, domain and time step) are performed and in the grid independence study different grid types (tetrahedral, hexahedral and hybrid grid) are examined. Through this analysis, the significance of the choice of the grid type along with the need to always perform grid independence study is highlighted.

Even though previous studies have contributed significantly to our understanding on CFD models performance in hydrogen/helium dispersion, a study which compares the whole range of turbulence modelling approaches against a single experiment has not been carried out. Thus, the second aim of the current work is to evaluate several turbulence modelling approaches against a single case of practical interest: jet release of buoyant gas inside a real-scale enclosure at low-Reynolds number with engineering application on hydrogen leaks. The evaluation of turbulence models is essential for the accurate prediction of the gas distribution. Unfortunately, despite the major research effort in the study of turbulent phenomena, turbulence is not fully understood yet. To simulate turbulent flows, two main turbulence modelling approaches exist: Reynolds-averaged Navier Stokes (RANS) and Large Eddy Simulation (LES) [15][16][17][18]. RANS approach is the most widely used and includes several well-known models such as $k-\varepsilon$ [19] and $k-\omega$ [15], which have been proved to work successfully in many engineering and physical problems. On the other hand, LES [18] is considered as a more accurate approach because part of the turbulence is resolved. Therefore, it can provide reliable results in a wider range of flows and applications. Its drawback is the high computational resources that are required. However, the growth in computing power over the last decades renders LES a possible choice for real scale engineering applications. A recent review on turbulence modelling is presented in [20].

For the analysis, an experiment carried out by French Atomic Energy Commission (CEA) [21] is used, which involves helium release $(18 \mathrm{Nl} / \mathrm{min})$ in a real scale room representative of a single private garage. Helium is used instead of hydrogen for safety reasons. This is a common practice because the two gases have similar dispersion behaviour. He et al. (2016) [22] performed CFD simulations of a reduced scale helium experiment in order to assess three similarity laws for the estimation of an equivalent (to helium) hydrogen flow rate and it was found that the assumption of equal volumetric flow rates give similar concentrations (differences around 5.5\%) no matter what the released gas was (hydrogen or helium). A similar comparison was made also by Prabhakar et al. (2017) [23] and the agreement between the results of the two gases was very good. To further examine the validity of this assumption under the conditions of the examined experiment a simulation with hydrogen release was initially performed and compared with its counterpart with helium release.

The current experiment was selected for the following reasons: 1) it is real scale geometry of practical interest, 2) many measurements points for consistent comparison are available and 3) it is 
an interesting benchmark for the turbulence models due to its low-Reynolds number release. The CFD independent results are compared and evaluated against the measurements using both the time series comparison and the statistical analysis. Narrower acceptable ranges for the Statistical Performance Measures (SPMs) are suggested for releases in indoor configurations compared to open environments.

\section{Description of experiment}

For this benchmark Test 4 from the experiments conducted by CEA [21] is chosen. In Figure 1 photographs from the experimental facility are shown and in Figure 2 the computational geometry of the facility and the sensors' position is presented. The room is completely sealed with only one small circular vent near the bottom of a vertical wall, which is kept open in order to maintain the facility at constant atmospheric pressure for the duration of the tests. Helium is released upwards from a $29.7 \mathrm{~mm}$ diameter pipe. The flow at the pipe exit is fully developed and the Reynolds number is equal to 115 . The release duration is equal to $3740 \mathrm{~s}$ (release phase). After that time, the helium release is ceased and the diffusion phase starts in which the concentration field changes mainly due to diffusion and the remainder velocity field. The diffusion phase lasted several hours in order to measure the concentrations. In this study, the measurements until $20000 \mathrm{~s}$ are used for comparison with the simulations results.

Table 1 summarizes the experimental parameters. The reference point of the facility is situated at a lower corner of the enclosure, as shown in Figure 1 and Figure 2. For an extensive concentration measurement, 64 monitoring points (sensors) were used inside the room. Figure 2 (bottom) displays the position of the sensors. For the sensitivity study of simulations (Section Sensitivity studies based on BPG) the results of the sensors M3N1, M3N3 and M3N5 with coordinates (2920, 1002, $315 \mathrm{~mm})$, $(2920,1004,945 \mathrm{~mm})$ and $(2920,1001,1575 \mathrm{~mm})$, respectively (Figure 2) are used. These sensors were chosen because their results are representative of the results of all sensors. They also cover different heights and they are close to the release point where stronger gradients exist compared to other points in the enclosure. For the comparison with the experiment (Section Comparison with the experiment and discussion), the time series at four additional sensors are presented: M2N2 and M2N4 which are located far from the release at different heights, P2N3 which is near the ceiling far from the release and P5N3 which is near the ceiling above the release. Finally, all monitoring points are considered in the statistical analysis performed (Section Comparison with the experiment and discussion).
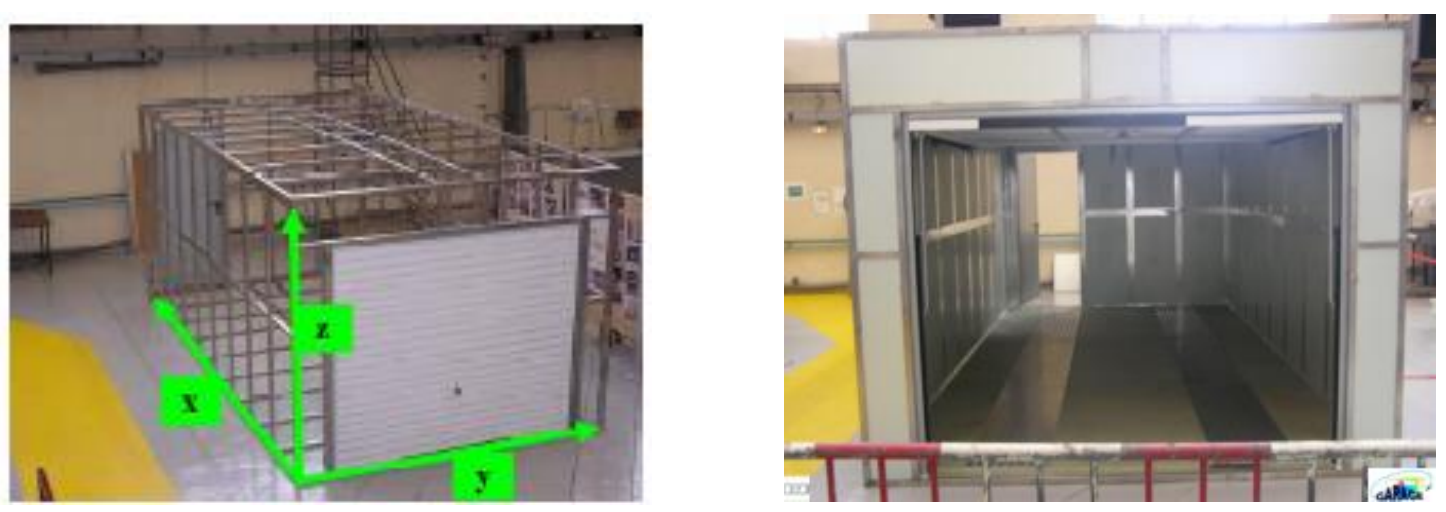

Figure 1. Photographs of the garage facility [21]. 


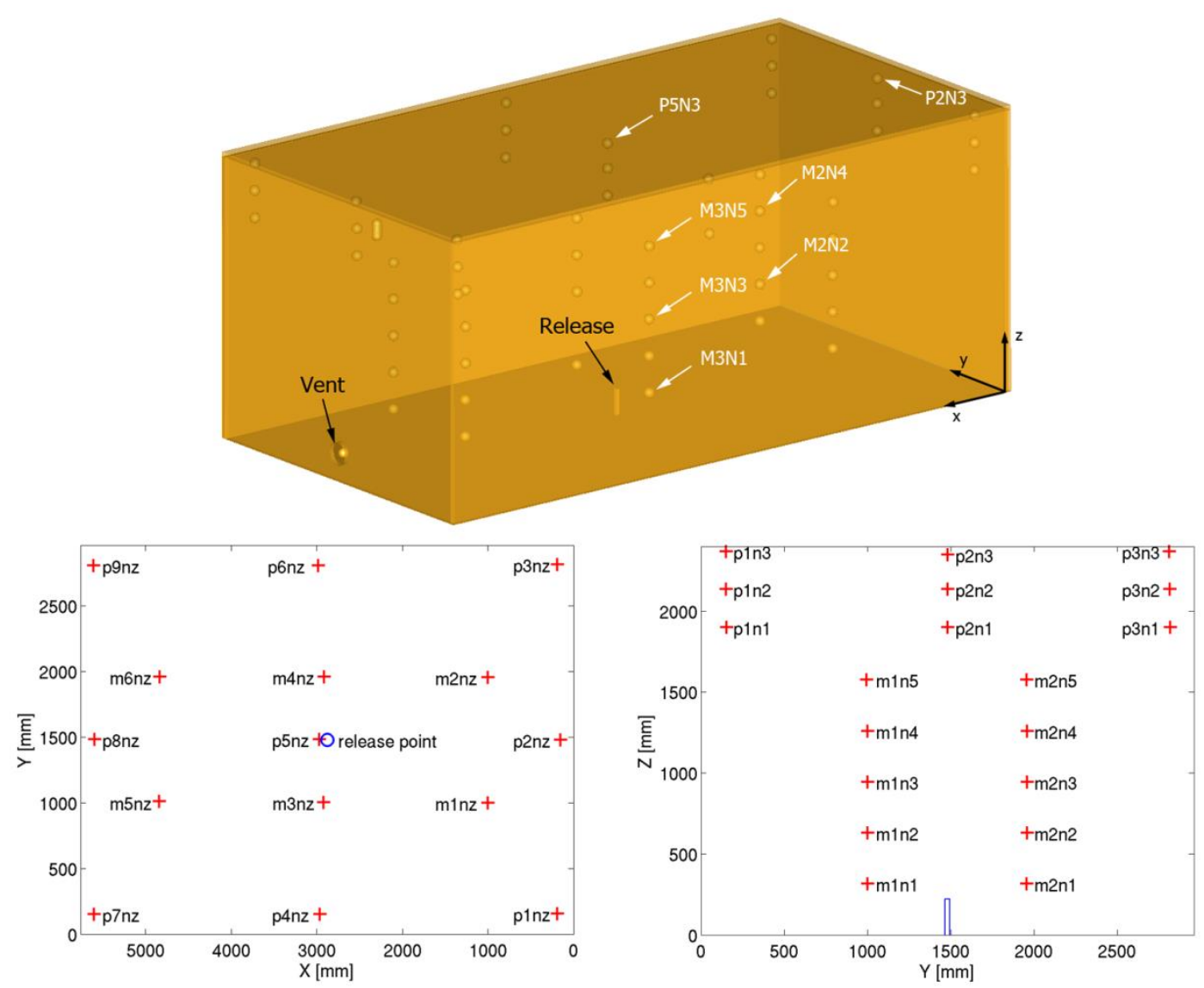

Figure 2. Geometry of the facility (top) and schematic diagram of top view (bottom, left) and side view (bottom, right) indicating sensors position.

Table 1. Experimental parameters.

\begin{tabular}{lc}
\hline \multicolumn{1}{c}{ Parameter } & Value \\
\hline x-dimension (mm) & 5760 \\
y-dimension (mm) & 2960 \\
z-dimension (mm) & 2420 \\
Release x-position (mm) & 2880 \\
Release y-position (mm) & 1480 \\
Release z-position (mm) & 220 \\
Release diameter (mm) & 29.7 \\
Vent diameter (mm) & 200 \\
Center of the vent x-position (mm) & 5760 \\
Center of the vent y-position (mm) & 1485 \\
Center of the vent z-position (mm) & 235 \\
Volumetric flow rate - STP (NL/min) & 18 \\
\hline
\end{tabular}




\begin{tabular}{lc}
\hline Exit velocity $(\mathrm{m} / \mathrm{s})$ & 0.47 \\
Re at exit $\left(24.1^{\circ} \mathrm{C}\right)$ & 115 \\
Densimetric Froude number & 0.35 \\
Release duration $(\mathrm{s})$ & 3740 \\
Temperature $\mathrm{T}\left({ }^{\circ} \mathrm{C}\right)$ & 24.1 \\
\hline
\end{tabular}

\section{Scientific assessment}

According to parameters in Table 1 the flow inside the pipe is laminar, since the Reynolds number is below the critical value (approximately equal to 2300 for the transition from laminar to turbulent flow for pipe flows). Nevertheless, as the jet develops the velocity will be increased due to buoyancy acceleration $(F r=0.35)$ and thus the Reynolds number will increase too. Furthermore, the Reynolds critical value for jets is lower than for pipe flows. Versteeg and Malalasekera [24] suggest that Reynolds numbers above 10 would lead to turbulent jets, while Ungate et al. [25] refer that for non-buoyant jets Reynolds number above 500 could eventually become turbulent at some distance from the nozzle. Landa and McClintock [26] state that "It is known that, as distinct from flows in channels, jet flows are rarely, if ever, laminar".

Small scale hydrogen jet experiments with various Re numbers at pipe exit were conducted by Schefer et al. [27] and it was shown that for $R e=520$ transition to turbulence occurs at the distance of $60 \mathrm{~mm}$ from the pipe exit. For Re>885 a fully turbulent flow field was observed. Molkov and Shentsov [3] evaluated the performance of laminar and turbulence models ( $k-\varepsilon$ and Dynamic LES) for helium releases inside a vented enclosure with pipe Re numbers 39, 2863 and 6968 (laminar, transitional and turbulent flow inside the pipe). It was shown that for $R e=39$ the laminar model reproduces reasonably the gas distribution inside the enclosure similar to the LES model, while for both transitional and turbulent flow laminar model failed to give good results. This indicates that for $\mathrm{Re}=39$ the flow was laminar.

In the present study, where $R e=115$, it is not certain if the flow outside the pipe remains laminar or becomes turbulent. It is expected at some distance from the nozzle the jet to break down into turbulent eddies due to the instabilities that develop. However, when helium reaches the ceiling and starts to disperse in the room, velocities become lower and the flow is likely to transit to laminar. Laminar flow probably also occurs far from the release point and especially at the lower half of the enclosure during the entire release phase and also in the diffusion phase. Therefore, both laminar and turbulence models were tested to assess their performance in simulating buoyant gas release and mixing at low flow rate inside the closed facility.

Initially, the laminar model is used. Next, the most widely adopted approach for turbulence, the RANS approach, is used. Two different RANS models are evaluated, the $k-\varepsilon$ model and the SST (Shear Stress Transport) transitional model. The $k-\varepsilon$ model is a well-established model with well predictive capabilities for fully turbulent flows. In this benchmark, the flow is more likely to be transitional along the jet core. Thus, within the scope of this study is the evaluation of $k-\varepsilon$ performance model in buoyant flows with low-Reynolds leak rate, which can be transitional. In addition, the SST transitional model was used because it is an advanced model which resolves better the near-wall region and has well predictive capabilities, especially for transitional flows.

The LES approach is also evaluated. LES is considered as a method with higher accuracy than the RANS technique because part of the turbulence is resolved. Its drawback is that it requires higher computational resources. However, as computer technology and parallel computations are increasingly developed, LES approaches gain ground in simulations. LES modelling approaches 
have in general well predictive capabilities in all flow regions (laminar, transitional and fully turbulent flows). A recent study with simulation of buoyant flow inside vented facility at various leak Re numbers [3] showed that Dynamic LES demonstrates satisfactory accuracy for all regimes. In the present study, in addition to the Dynamic LES, the RNG-LES and the classic and simpler Smagorinsky-Lilly (S-L) LES are also evaluated.

Finally, a hybrid model, the Detached Eddy Simulation (DES) model, is tested. The idea behind DES is to switch from the SST-RANS to LES in regions where the turbulent length predicted by the RANS model is larger than the local grid spacing [28]. In this case, the length scale used in the computation of the dissipation rate in the equation for the turbulent kinetic energy is replaced by the local grid spacing.

\section{Simulation setup}

The conservation equations of mass and momentum for the air-helium mixture and the conservation equation for helium mass fraction are solved. The key parameters of the modelling strategy follow the BPG [13] and are similar in all simulations:

- the computational domain is extended beyond the wall with the vent (see Figure 3), in order to avoid applying boundary conditions exactly on the opening,

- the vent is discretized with at least two Control Volumes (CV) in z-direction in order to allow inflow and outflow and grid refinement was imposed near the leak and near the ceiling (due to the buoyant nature of helium).

- domain, grid and time step independence studies are performed to define the appropriate domain extension, grid size and time step in terms of both accuracy and computational economy. All sensitivity studies are briefly presented in Section 5.

Three CFD codes are used for the simulations: ANSYS CFX 15.0, ADREA-HF and ANSYS Fluent 14.5. Based on the CFD code that was used a different modelling approach might be applied due to code constraints, e.g. options in grid type and numerical schemes. However, the final comparison with the experimental results (Section 7) is performed using the independent results obtained by the sensitivity studies. In that way, the numerical effects are minimized and a consistent comparison is enabled.

\section{$4.1 \quad$ Release modelling}

In all simulations, the release area is the same as that in the experiment (Table 1). However, two different source modelling approaches were followed. In the first approach (3D pipe), the flow inside the pipe was simulated. The inlet cross-section was positioned $5 \mathrm{~cm}$ from the pipe exit. The pipe axis, from the inflow boundary to the pipe exit, was discretized using 5 cells with uniform size. The release was initiated through the velocity inlet boundary condition with 100\% helium and uniform velocity along the inlet cross-section with no turbulence. In the second approach (source area at the exit pipe), the helium inlet was modelled as a circular source area on the face of the control volume located exactly at the pipe exit (no modelling inside the pipe). This approach was tested and compared with the first approach using the ADREA-HF code and showed that they both give identical results. Thus, in CFX and FLUENT simulations, the first approach was used, while in ADREA-HF the second approach was employed for simplicity.

Another feature of ADREA-HF code, which differs from the other codes, is that it uses Cartesian grid and to combine irregular geometry with the grid, the porosity method is employed [29]. Based on the porosity method the cells (CV) that are entirely blocked by solid obstacles have a porosity value equal to 0 , while the entirely free cells have a porosity value equal to 1 . The partially blocked cells have values between $0-1$. The fully blocked cells are excluded from the calculations and the memory allocations, while for the partially blocked cells the integration of the conservation 
equations is performed over the active (free) cell volume. Face areas of the control volumes have similar treatment. In the present case where the nozzle and the vent are circular, partially blocked cells exist around their circumference. Therefore, to check the consistency of that method, additional simulations were performed using square-shaped inlet of the same area as the circular one and a square-shaped vent of the same area as the circular vent so as the Cartesian gridlines to be aligned with the geometry. The simulations showed that there is no significant effect on the results.

\subsection{Turbulence modelling}

In the present study, RANS, LES and laminar approach were used and their performance was evaluated against the measurements. In RANS approach the time-averaged conservation equations are solved and an instantaneous quantity is decomposed into its time-averaged and fluctuating quantities. To compute the fluctuating quantities (Reynolds stresses) the turbulent eddy viscosity concept is employed. For the turbulence closure of the governing RANS equations, the conservation equations of certain turbulence characteristics (e.g. turbulence kinetic energy and dissipation rate) are solved based on the model. LES approach is considered as a method with higher accuracy than the RANS technique. Part of the turbulence is resolved, while the smallest length scales are modelled via low-pass filtering of the governing equations. Its drawback is that it requires higher computational resources. In the laminar model, the unsteady Navier-Stokes equations are solved and no turbulence model is applied.

In this study, the k- $\varepsilon$ and the SST RANS models are used. In the $k-\varepsilon$ model, the standard model [19] with extra buoyancy terms is used. The governing equations of $k-\varepsilon$ turbulence modelling approach are given in [30]. The turbulent Schmidt number, which is used for the calculation of turbulent diffusion coefficient in the conservation of species, was set equal to 0.72. In the SST turbulence model [31], the $k-\varepsilon$ model is applied in the free stream flow far from the walls, while the $k-\omega$ model is applied in the near wall layers. The transitional model (Gamma Theta Model) is based on two transport equations, one equation for the transition onset criteria in terms of momentum thickness Reynolds number and one equation for the intermittency. The Gamma Theta model is based on a new empirical correlation [32] which has been developed to cover standard bypass transition as well as flows in low free-stream turbulence environments. This built-in correlation has been extensively validated with the SST turbulence model for a wide range of transitional flows [32][33][34]. In SST simulations the turbulent Schmidt number was set equal to 0.9.

For the evaluation of the LES approach, the S-L LES, RNG-LES and Dynamic LES are used and their governing equations are given in [26], [35] and [3], respectively. In S-L LES, the value of 0.1 was used for the Smagorinsky constant as it is frequently used in hydrogen cases. In RNG-LES the Smagorinsky constant is equal to 0.157 . In Dynamic LES, the value is calculated dynamically in every cell based on the local characteristics of the flow. The turbulent Schmidt number was set equal to 0.72 and 0.70 in S-L and Dynamic LES, respectively, whereas in RNG-LES it is calculated dynamically [36].

\section{Sensitivity studies based on BPG}

\subsection{Domain independence study}

Based on the BPG that have been presented in [13] sensitivities studies are essential, in order to obtain accurate and numerical-effect-free results (as much as possible). As mentioned in Section Simulation setup, the domain is extended outside the garage in order to avoid applying boundary conditions directly to the vent. This practice is considered necessary (see also [13], [37]), because applying the boundary exactly at the vent opening can affect the results significantly as it is demonstrated in Figure 3. Without domain extension, the predicted concentrations are significantly under-predicted. In all ADREA-HF simulations an extension outside the vent equal to $1 \mathrm{~m}$ was found to be sufficient. In CFX simulations, domain extension sensitivity study was conducted for the 
SST model and an extension equal to $2 \mathrm{~m}$ was found to provide domain-size independent results. This extension was used in all CFX simulations, while in FLUENT simulations, an extension of $2.5 \mathrm{~m}$ was chosen based on modellers' experience.
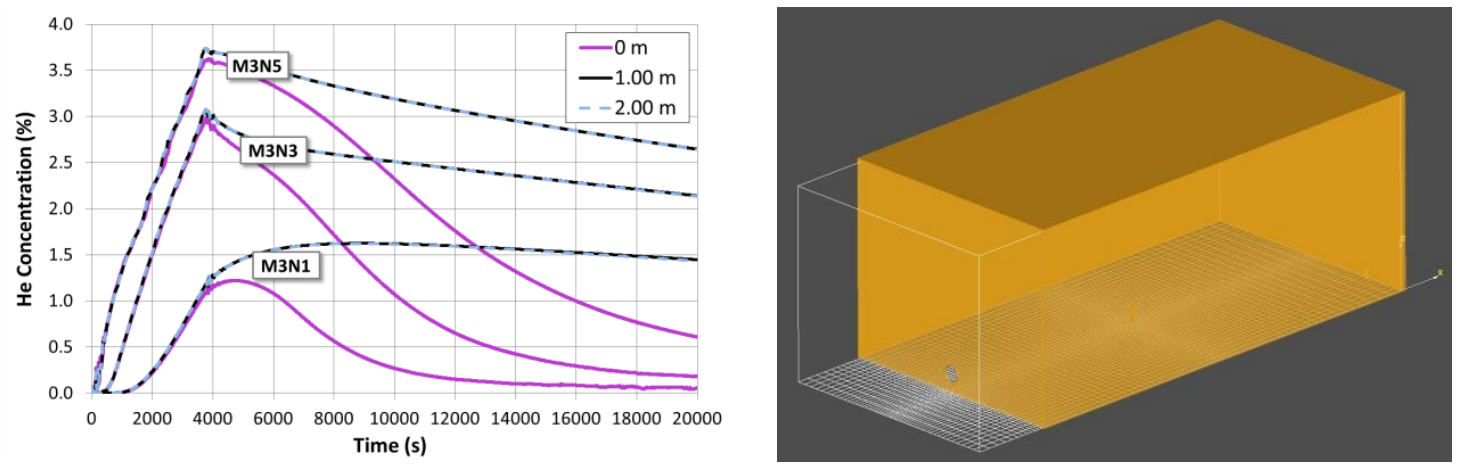

Figure 3. Left: Domain sensitivity study using the $k-\varepsilon$ model. Helium volume concentration time-series at three sensors for various horizontal extensions of the domain. Right: Computational domain with $1 \mathrm{~m}$ extension outside the vent along with the geometry and the grid at $\mathrm{z}=0$ plane (ADREA-HF).

\subsection{Boundary conditions}

Different boundaries conditions were used at the open boundaries of the area outside the garage according to the available options of the CFD codes. The conducted domain size sensitivity study ensures that the applied boundary conditions do not influence the results. In ADREA-HF code, for $k-\varepsilon$ and laminar model, the constant pressure boundary condition was applied on the top boundary and zero gradient on the rest. For LES, a non-reflecting type boundary condition was imposed in all open boundaries. In CFX code, an opening type of boundary condition was imposed on the top plane, while the side boundaries were modelled as symmetry planes. In FLUENT code, the "pressure outflow" condition was set at the domain boundaries with the same temperature as in the domain and the gauge pressure equal to zero.

\subsection{Grid independence study}

Grid independence study is essential and should be performed separately for each different modelling approach. Therefore, we carried out separate grid sensitivity study for each CFD code and each turbulence model.

In the ADREA-HF-laminar case, three different grid sizes were tested consisting of 158,226 , 416,521 and 594,032 cells. The number of cells which discretize the release area is equal to 1, 9 and 25 respectively. Cells size increases away from the release point in order to reduce the total number of cells. The maximum expansion ratio (ratio of two adjacent cells size) was equal to 1.05 in the two first grids and 1.12 in the third one. All grids gave similar results as shown in Figure 4 (left). A view of the coarsest grid at $\mathrm{z}=0$ plane can be seen in Figure 3 (right).

In CFX-laminar case, two types of grid were used: a hybrid grid (tetrahedral in the core of the jet and near the ceiling and hexahedral cells in the rest of the domain) as shown in Figure $\mathbf{5}$ and a hexahedral grid. The results of the two hybrid grids, consisting of 470,000 and 2,860,000 nodes, and of the hexahedral grid along with the measurements are presented in Figure 4 (right). It can be observed that grid independence was not achieved. Finer grids could not be tested due to the prohibitively high computational cost and thus the comparison with the measurements in Section Comparison with the experiment and discussion is not presented for the CFX-laminar case. 

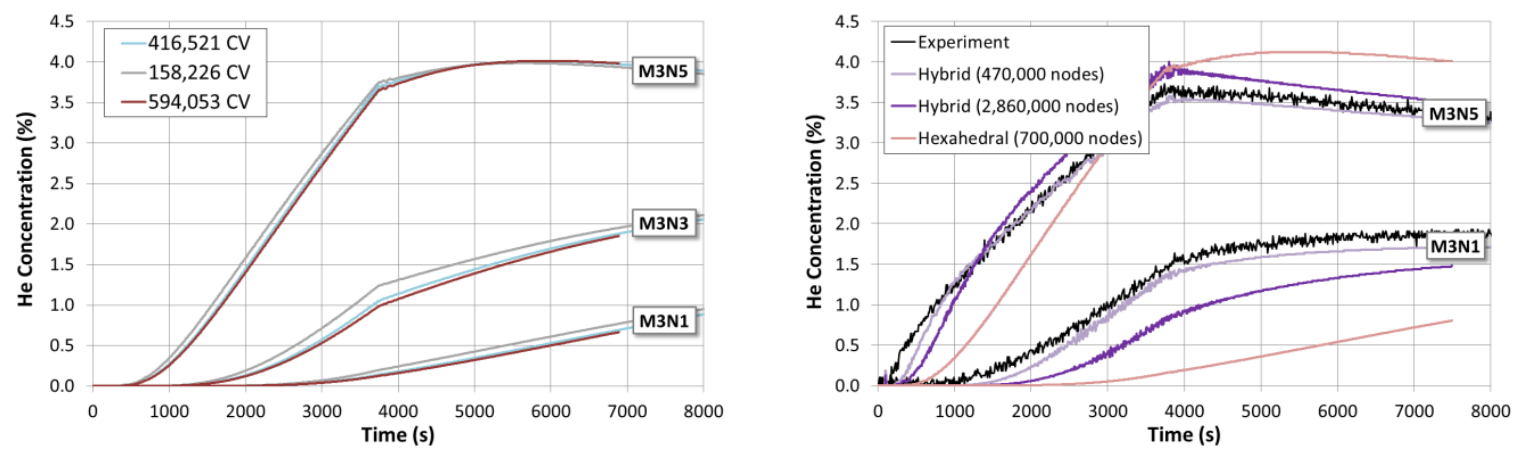

Figure 4. Grid independence study for the laminar model. Left: Cartesian grid (ADREA-HF). Right: Hybrid and hexahedral grids (CFX). Helium volume concentration time-series.

Based on Figure 4 (right), hexahedral grid leads to less diffusive results and thus the concentrations at the bottom sensors are seriously under-predicted compared to both the experiment and the predictions with the hybrid grid. According to this behaviour, we can conclude that the tetrahedral grid provides significant numerical (false) diffusion. Even though the results with the hybrid grid consisted of 470,000 nodes are in very good agreement with the measurements, the laminar model is not appropriate for the examined case. The good performance of the coarser grid is attributed to the numerical diffusion, which leads to a greater level of mixing. This is also supported by the performance of the fine hybrid grid, which tends to approach the results of the hexahedral grid and the ADREA-HF-laminar independent results. To avoid such complexities and inaccuracies hexahedral grid is recommended for similar applications.

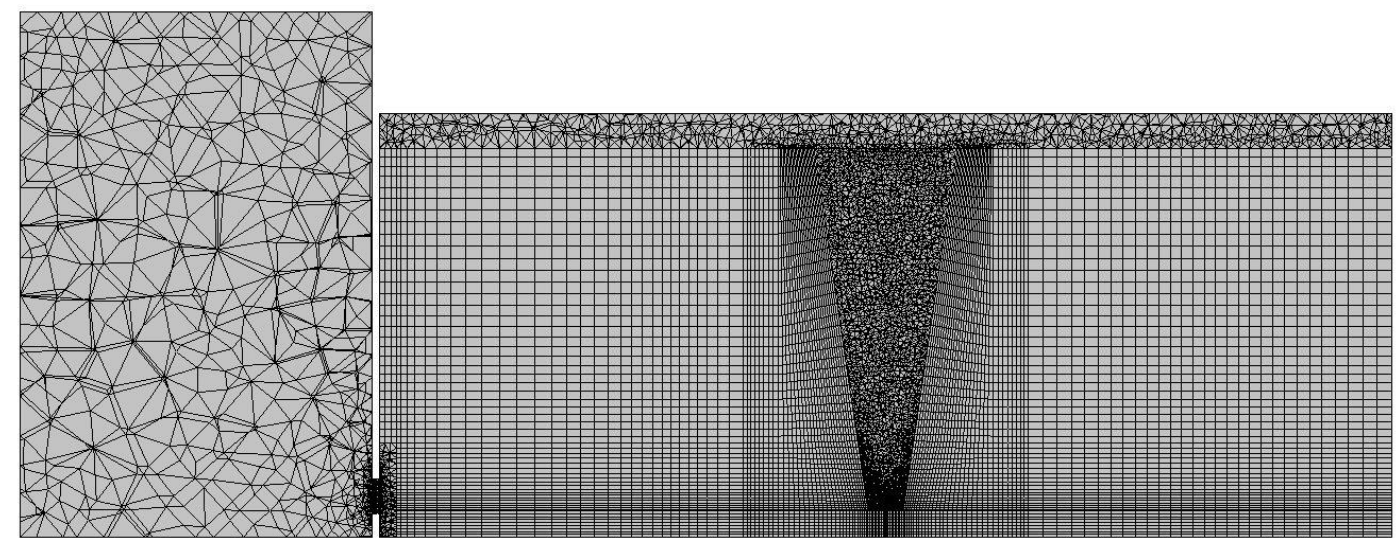

In the $k-\varepsilon$ model, three different grid sizes of $158,226,3,522,198$ and 807,723 cells were tested using 1, 4 and 9 cells discretization along the release, respectively. The maximum expansion ratio was equal to 1.05 in all grids. The differences among the results were minor and therefore the results of the coarse grid are considered grid-independent.

In the SST case, two grid types were used in order to assess grid independence: hybrid grid (as in the laminar case) and hexahedral grid. In the hybrid grid, three different grid sizes were tested consisting of 110,000, 470,000 and 2,860,000 nodes and the results are presented in Figure 6 (left). Here the false diffusion produced by the tetrahedral grid is less enhanced compared to the laminar case, probable because turbulent diffusion prevails over numerical diffusion.

315 In hexahedral grid case, grids with 120,000, 700,000 and 2,200,000 nodes were examined. In Figure 6 (right) the hexahedral grid independence study is shown in two sensors. The results with the three 
grids are almost identical in all sensors except from the bottom ones, where small discrepancies are observed. Thus, the hexahedral grid consisted of 700,000 nodes was used for comparison with the measurements in Section Comparison with the experiment and discussion.
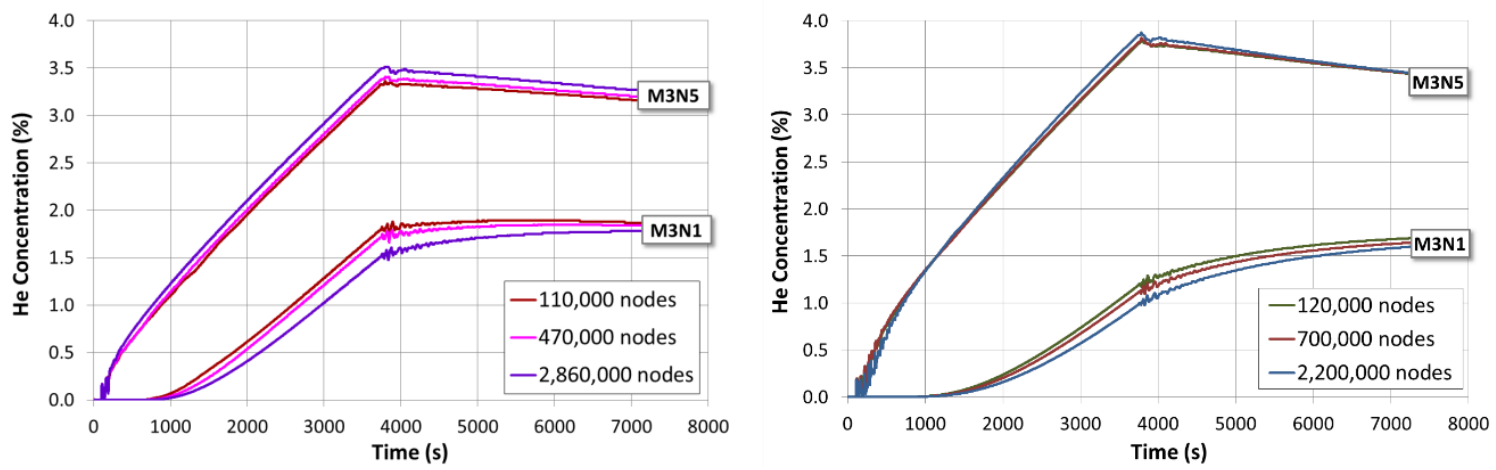

Figure 6. SST grid independence study with hybrid grid (left) and hexahedral grid (right). Helium volume concentration time-series at two sensors.

In the RNG-LES case, three different Cartesian grids were tested consisting of 158,226, 558,185

and 757,381 cells (1, 4 and 9 cells discretization of the release respectively) whereas in the S-L LES case only the first two grids were evaluated. The maximum expansion ratio was equal to 1.05. Figure 7 (left) presents the results of the RNG-LES grid independence study. Small differences in the results are observed, and thus, the results with the coarse grid are compared with the experiment in Section Comparison with the experiment and discussion.
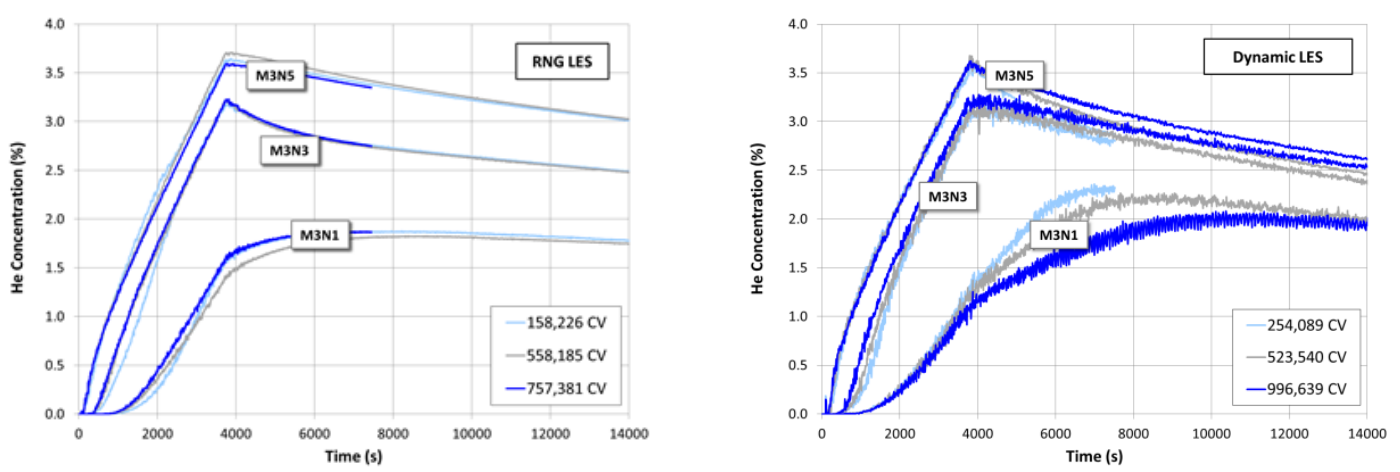

Figure 7. Grid independence study for RNG-LES (left) and Dynamic LES (right). Helium volume concentration time-series at three sensors.

In the Dynamic LES case, a grid independence study was performed using three block-structured hexahedral computational grids and is presented in Figure 7 (right). All three grids have the same inlet resolution in the form of a polygon inscribed in a circle of 9 cells across the diameter and with cross-section area of 45 cells (Figure 8). For the vent resolution, a polygonal with 10 cells across the height and 11 across the width with a total area of 74 cells was used. Small differences are detected which are more pronounced in the diffusion phase. At the bottom sensors and during the diffusion phase, the finer grid $(996,639 \mathrm{CV})$ gives different results compared to the coarse $(254,089 \mathrm{CV})$ and medium grid $(523,540 \mathrm{CV}$ ) by maximum $28 \%$ (compared to the medium grid). Finer grids could not be tested due to the prohibited high computational time. However, we should also keep in mind that it is difficult to achieve strict grid independence in LES due to the intrinsic dependence of the method from the grid. Therefore, in this case, results with the finer grid are used for comparison in Section Comparison with the experiment and discussion. 


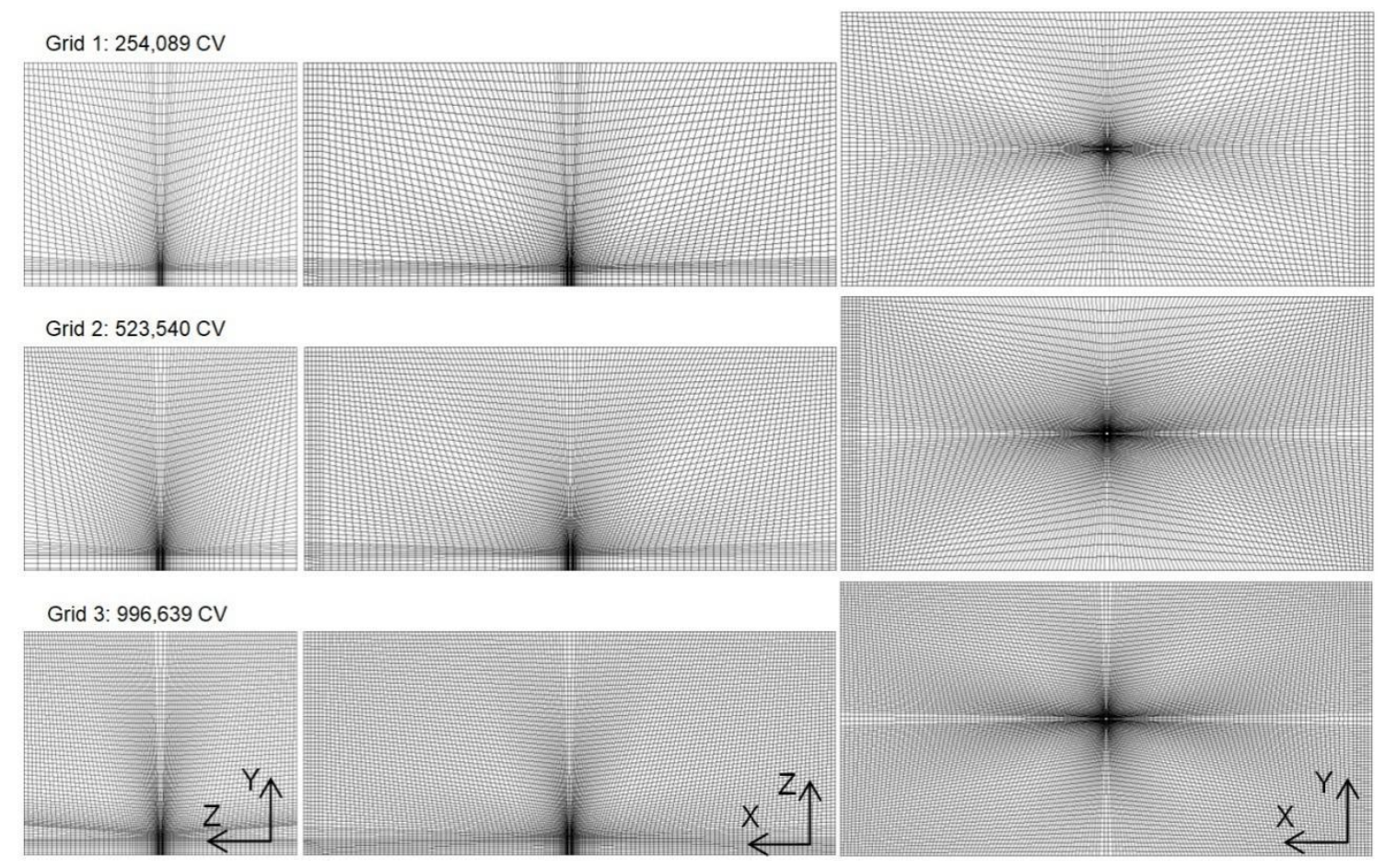

Figure 8. Centerline cross sections for Dynamic LES for the three different grid sizes: $x=0$ (left), $y=0$ (middle), $\mathrm{z}=0$ (right).

In the DES case, grid independence study was performed testing three hybrid grids with with hybrid grid, grid independence was not achieved. Finer grids could not be tested due to the prohibitively high computational cost and thus the DES predictions are not compared with the measurements in Section Comparison with the experiment and discussion.

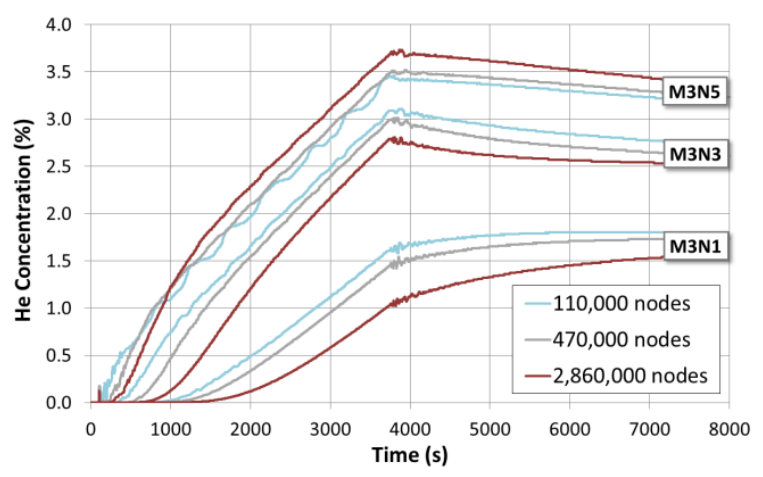

Figure 9. Grid independence study for the DES. Helium volume concentration time-series at three sensors.

It should be highlighted that LES grid independence analysis, and consequently DES analysis, requires special attention. As explained by Gullbrand [38], when explicit filtering is used, the explicit filter width has to be kept constant while the computational grid is refined to obtain a grid-independent solution. With implicit filtering (as it is used here), since the filter is directly connected to the grid resolution, the solution converges towards a Direct Numerical Simulation (DNS) as the grid is refined, and not towards the filtered Navier-Stokes equations. Moreover, in the DES model, there is a further complication that is the switch between the RANS-SST model and the LES model that can also be affected by the grid resolution. The overall results of the above 
mechanisms is that in the exact same location, according to the selected grid resolution (coarse, finer, finest), different models could be applied by the code e.g. RANS or LES and subgrid modelling or no subgrid modelling.

Furthermore, the grid independence analysis showed that a finer grid resolution causes a worsening of the model accuracy in several sensors. The same behaviour for the DES model was shown also by Gant [39] and was partly explained by Geurts [40], at least for the LES model. The total error is the sum of the modelling error and the discretization error. The two errors have opposite effects and tend to compensate each other. In the coarse grid, the modelling error is partly cancelled out by the discretization error and the total error is small. Geurts [40] comments that "In fact, the discretisation error effect decreases with increasing resolution and the total error approaches the modelling error. However, this modelling error is by itself larger than the total error on coarser grids. This arises because on coarse grids the comparably large discretisation error effects partially cancel the modelling error effects."

\subsection{Time step sensitivity study}

Finally, a time step sensitivity study has been conducted as recommended by the BPG. For space economy, we are not presenting any graph here. In ADREA-HF laminar and $k-\varepsilon$ simulations, the time step was determined by restricting the CFL (Courant-Friedrichs-Lewy) number to be lower or equal to 10. Lower CFL numbers (equal to 2 in the laminar case and equal to 5 and 20 in the $k-\varepsilon$ case) that were tested had no impact on the results. In LES, a smaller time step is generally required compared to RANS approaches for numerical stability and for a better reproduction of the resolved turbulence. Thus, a CFL $=0.9$ restriction was imposed. In the RNG-LES other values were also examined, equal to 0.1 and 0.3 and 1.8, and no differences were found in the results.

In FLUENT (Dynamic LES), the time step was limited to $0.02 \mathrm{~s}$ to keep CFL number below 1, in order to avoid divergence problems during the release phase. After termination of the release, the time step was increased to $0.2 \mathrm{~s}$ in order to save computational time. Two additional simulations with time step 0.1 and $0.05 \mathrm{~s}$ during the diffusion phase were performed (using the finest of the examined grid) and the results were unaffected.

In CFX simulations, a time step sensitivity study for the SST model was performed, using time steps equal to $0.1,1.0$ and $5.0 \mathrm{~s}$. The results of 0.1 and $1.0 \mathrm{~s}$ were identical and thus the value of $1 \mathrm{~s}$ was used in all CFX simulations.

\section{Statistical Performance Measures and Quantitative Assessment Criteria}

Statistical Performance Measures (SPMs) [41][42] provide a comparison between the predictions and the measurements and are very useful for model evaluation. Several SPMs are available and each of them has its merits and drawbacks. In the present study the SPMs proposed by Chang and Hanna [43] are used, i.e. fractional bias (FB), normalized mean square error (NMSE), geometric mean bias (MG), geometric mean variance (VG) and factor of $n$ (FACn) i.e. the fraction of predictions to measurements ratios which are between $n$ and $1 / n$.

FB and MG indicate under/over-prediction of the model, while NMSE and VG indicate the scatter of the data. Positive values of FB and values larger than unity of MG indicate an overall under-prediction of the model. However, it is possible for a model to perform poorly and still have $\mathrm{FB}=0$ and $\mathrm{MG}=1$ when under-predicted values are perfectly counterbalanced by over-predicted ones. FACn measure is easy to understand and interpret, as it indicates the fraction of data that have a relative error less or equal to a certain value, e.g. FAC2 indicates the fraction of data whose relative error is less than or equal to $100 \%$. It is the most robust and consistent measure, because it is not highly influenced by outliers, and thus it is highly recommended for model evaluations. 
MG and VG are undefined for zero values. Therefore, for their calculation, a threshold can be used as the lower bound for both predicted and measured values [43]. In the present study, a threshold equal to $10^{-4}$ is applied.

The acceptable limits of the SPMs for a "good" model cannot be defined as straightforward. In atmospheric releases a "good" model is expected to have $|\mathrm{FB}|<0.3$ or $0.7<\mathrm{MG}<1.3$, and NMSE $<1.5$ or $\mathrm{VG}<4$ [43]. These relatively large limits have been identified taking into account the large uncertainties in the definition of accurate weather conditions like wind direction and speed and the stability class. These limits are quite wide for indoor releases and even a model that performs poorly can give values within this range. Therefore, narrower limits should be considered for the acceptable ranges for indoor releases.

To set stricter quantitative assessment criteria we relate SPMs with the relative error of predictions. Figure 10 shows the value of FB as calculated assuming that the predictions at all sensors have a relative error with respect to the measurements equal to 5, 10, 20 and 30\%. Practically this means that if the computational results have for example maximum relative error $5 \%$, the absolute value of FB will be smaller than or equal to 0.05 .

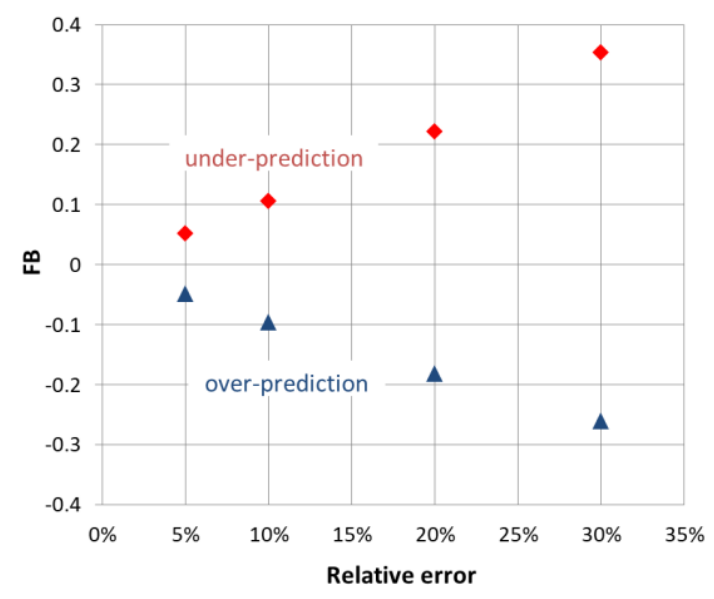

Figure 10. The values of FB for several relative errors of the predictions.

Table 2 presents the SPMs if it is assumed that the relative error of the computational results is $20 \%$ for the entire dataset. These narrower criteria can be used to give an insight on how models perform in indoor releases. Values within this range $(-0.18<\mathrm{FB}<0.23, \mathrm{NMSE}<0.05,0.83<\mathrm{MG}<1.25$ and $\mathrm{VG}<1.05$, FAC1.2) would imply that the results have less than $20 \%$ relative error over the entire dataset and can be considered as acceptable for indoor releases.

Table 2. Statistical Performance measures (SPMs) for specific relative error for the entire dataset.

\begin{tabular}{cccc}
\hline SPM & Ideal value & $\mathbf{2 0} \%$ over-prediction & $\mathbf{2 0 \%}$ under-prediction \\
\hline FB & 0 & -0.18 & 0.23 \\
NMSE & 0 & 0.034 & 0.05 \\
MG & 1 & 0.83 & 1.25 \\
VG & 1 & 1.034 & 1.05 \\
\hline
\end{tabular}




\section{Comparison with the experiment and discussion}

\subsection{Comparison against an equivalent hydrogen release.}

In order to verify the validity of the assumption that helium is a good surrogate of hydrogen [21], [22], a simulation with hydrogen release was initially performed using the same volumetric release rate as in helium. The simulation was performed using the $k-\varepsilon$ model, because it achieves satisfactory agreement with the experiment with low computational time (see Section 7.2). The predicted volume concentrations of helium and hydrogen were almost identical at all sensors. The fact that hydrogen and helium have very similar molecular diffusion coefficients in air (7.8e-05 and $7.2 \mathrm{e}-5 \mathrm{~m}^{2} / \mathrm{s}$, respectively) contributes to the similarity of the results. Based on the abovementioned, it is shown that helium has similar dispersion behaviour with hydrogen under the conditions of the examined experiment and taking into account also the findings of a previous study [22], helium is a good surrogate of hydrogen for dispersion studies. Consequently, the helium concentrations derived in the next section can be considered to be hydrogen concentrations of equivalent release, in order to be able to draw conclusions related to hydrogen safety in similar applications.

\subsection{Comparison with the experiment}

In this section, the computational results are compared with the experiment. Only the simulations that achieved independent results in Section Sensitivity studies based on BPG are presented here. The main numerical characteristics of these simulations are summarized in Table 3.

Table 3. Summary of numerical characteristics for the cases compared with the experiment.

\begin{tabular}{|c|c|c|c|c|c|}
\hline Case & CFD code & Grid & $\begin{array}{c}\text { Numerical } \\
\text { scheme for } \\
\text { convective terms }\end{array}$ & $\begin{array}{c}\text { Transient } \\
\text { numerical } \\
\text { scheme }\end{array}$ & $\begin{array}{c}\text { Release } \\
\text { modelling }\end{array}$ \\
\hline laminar & ADREA-HF & $\begin{array}{c}\text { Cartesian } \\
\text { Hexahedral } \\
(159,885 \mathrm{CV})\end{array}$ & MUSCL (TVD) & $\begin{array}{l}1^{\text {st }} \text { order } \\
\text { implicit }\end{array}$ & $\begin{array}{l}\text { Source area at } \\
\text { the exit pipe }\end{array}$ \\
\hline $\mathrm{k}-\varepsilon$ & ADREA-HF & $\begin{array}{l}\text { Cartesian } \\
\text { Hexahedral } \\
(159,885 \mathrm{CV})\end{array}$ & MUSCL (TVD) & $\begin{array}{l}1^{\text {st }} \text { order } \\
\text { implicit }\end{array}$ & $\begin{array}{l}\text { Source area at } \\
\text { the exit pipe }\end{array}$ \\
\hline SST & CFX 15.0 & $\begin{array}{c}\text { Hexahedral } \\
\text { (700,000 } \\
\text { nodes })\end{array}$ & $\begin{array}{c}\text { High resolution } \\
{[44]}\end{array}$ & $\begin{array}{c}2^{\text {nd }} \\
\text { backward } \\
\text { Euler }\end{array}$ & 3D pipe \\
\hline RNG-LES & ADREA-HF & $\begin{array}{c}\text { Cartesian } \\
\text { Hexahedral } \\
(159,885 \mathrm{CV})\end{array}$ & $\begin{array}{l}\text { Central } \\
\text { differences for } \\
\text { momentum, } 2^{\text {nd }} \\
\text { order bounded } \\
\text { upwind for mass }\end{array}$ & $\begin{array}{l}\text { 2nd order } \\
\text { implicit }\end{array}$ & $\begin{array}{l}\text { Source area at } \\
\text { the exit pipe }\end{array}$ \\
\hline S-L LES & ADREA-HF & $\begin{array}{l}\text { Cartesian } \\
\text { Hexahedral } \\
(159,885 \mathrm{CV})\end{array}$ & $\begin{array}{l}\text { Central } \\
\text { differences for } \\
\text { momentum, } 2^{\text {nd }} \\
\text { order bounded } \\
\text { upwind for mass }\end{array}$ & $\begin{array}{l}\text { 2nd order } \\
\text { implicit }\end{array}$ & $\begin{array}{c}\text { Source area at } \\
\text { the exit pipe }\end{array}$ \\
\hline $\begin{array}{l}\text { Dynamic } \\
\text { LES }\end{array}$ & $\begin{array}{c}\text { ANSYS } \\
\text { FLUENT } 14.5\end{array}$ & $\begin{array}{l}\text { Structured } \\
\text { Hexahedral }\end{array}$ & $\begin{array}{l}2^{\text {nd }} \text { order upwind } \\
\text { for mass and }\end{array}$ & $\begin{array}{l}\text { Bounded } \\
2^{\text {nd }} \text { order }\end{array}$ & 3D pipe \\
\hline
\end{tabular}




$$
\begin{array}{ccc}
(1,030,491 \mathrm{CV}) & \text { energy, } & \text { Implicit } \\
& \text { bounded central } & \\
& \text { differencing for } \\
& \text { momentum }
\end{array}
$$

Figure 11 shows the concentration time series for the laminar model. Based on the concentration time series, the laminar model performs poorly. It produces less diffusive results than the experiment and thus the concentration is seriously under-predicted in the lower part of the facility, whereas it is over-predicted in the upper part.

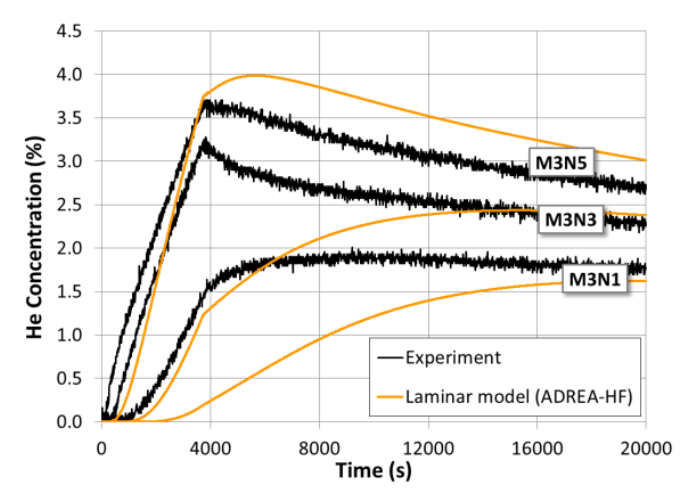

Figure 11. Helium volume concentration time series at three sensors for the laminar model (ADREA-HF) and for the experiment.

Figure 12 presents the concentration time series for the RANS (SST transitional and $k-\varepsilon$ ) models. Both models give very similar results, as expected. SST applies $k-\varepsilon$ model in the free stream flow and $k-\omega$ model near walls. Since there are no obstacles inside the enclosure, the SST model utilizes mainly the $k-\varepsilon$ model apart from the areas close to the walls, ceiling and floor. Still, even at the sensors located next to the walls (e.g. P2N3 and P5N3) the two models give almost identical results.

Comparing with the experiment, the predictions are in good agreement at most sensors. A minor over-prediction at the sensors located next to the ceiling (P2N3 and P5N3) is observed with the maximum discrepancy being equal to $8 \%$ at P5N3. At medium heights (sensors M3N3 and M2N4) the agreement with the experiment is very good, especially at sensor M2N4 which is located far from the release. In sensor M3N3, which is near the release, the concentration is under-predicted at early times (lower than $2000 \mathrm{~s}$ ) by a maximum of $45 \%$ while the prediction is improved at later times. In the lower part of the facility (sensors M3N1 and M2N2) a notable under-prediction of about $20 \%$ is observed.

A closer look in the results of sensors P2N3 and P5N3 which are located next to the ceiling but in different positions (the first one at the corner of the garage and the second one above the release point - see Figure 2), we observe that after the end of the release ( $3740 \mathrm{~s})$, the results are collapsed in a single time series in both experiment and simulations (lower right plot in Figure 12). This occurs because, in a given height, a uniform horizontal layer is formed almost immediately after the end of release resulting in negligible differences among concentrations. During the release phase, higher concentration levels are observed at sensor P5N3 than sensors P2N3 because P5N3 is located above the release point. 
The good performance of the RANS model compared to the laminar model predictions is attributed to the fact that turbulent diffusivity provides greater levels of mixing resulting in a less stratified mixture. This behaviour indicates that the flow becomes turbulent downwind the exit pipe.
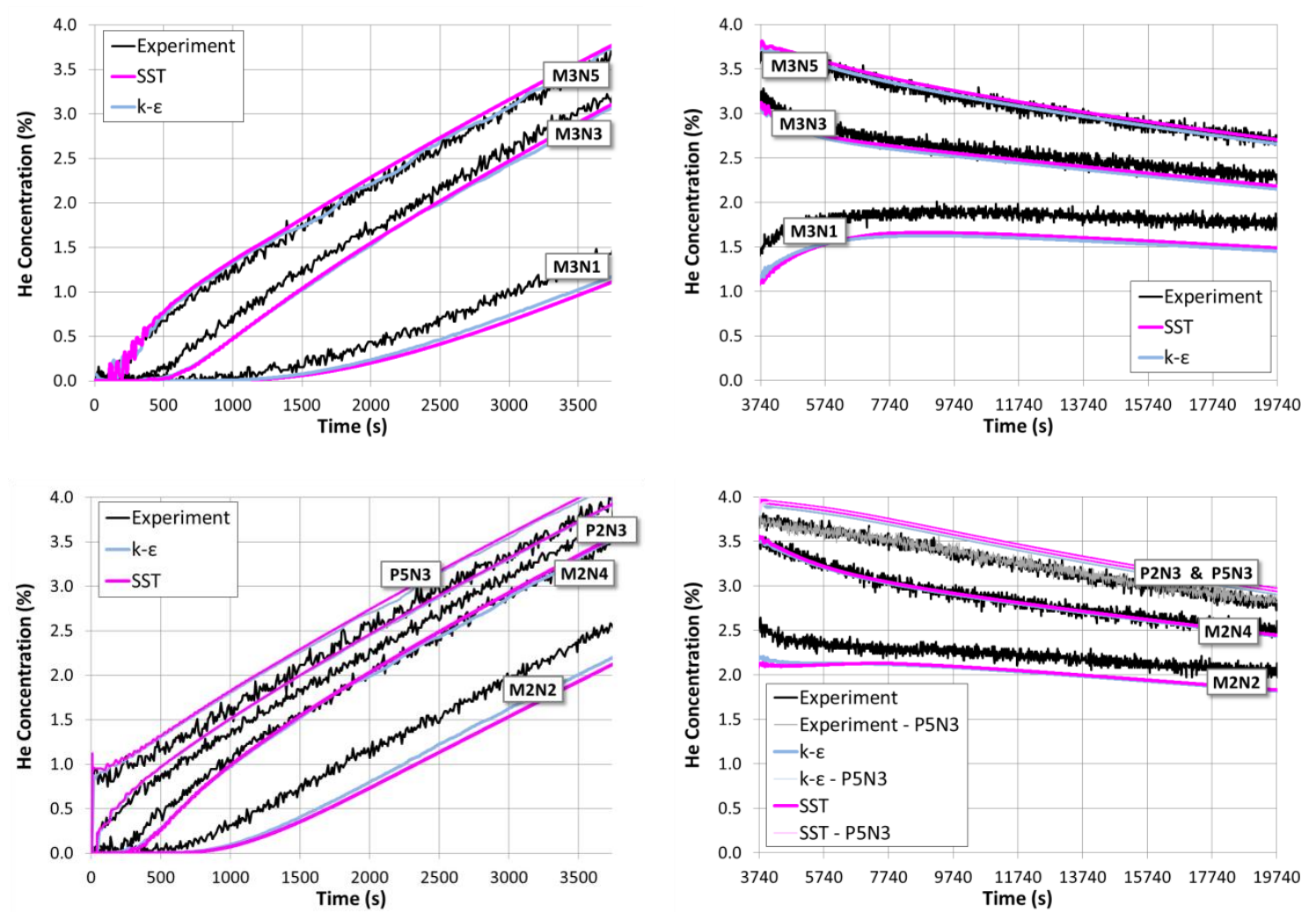

Figure 12. Helium volume concentration time series near the release point (top figures) and near the walls (bottom figures) for the RANS models and for the experiment during the release (left figures) and diffusion (right figures) phase.

However, during the diffusion phase (i.e. after $3740 \mathrm{~s}$ ) the flow is expected to become laminar due to the absence of helium release which is the main source of turbulence. Thus, one could anticipate the laminar model to perform well during that phase, but this is not the case based on Figure 11. The poor performance of the laminar model during the release phase affects negatively its performance in the diffusion phase, too. Therefore, to fairly assess the performance of the laminar model during the diffusion phase, an additional simulation was carried out.

That simulation with laminar model starts at the diffusion phase but it uses as initial conditions the flow and concentration field at $3740 \mathrm{~s}$ as obtained by the $k-\varepsilon$ simulation. This simulation was in good agreement with the experiment and gave results almost identical with the $k-\varepsilon$ prediction. The similar behaviour of the laminar and the $k-\varepsilon$ model at the diffusion phase is attributed to the small predicted values of $k$ and $\varepsilon$, which result in negligible turbulent viscosity compared to the molecular viscosity. This indicates that the flow at the diffusion phase becomes laminar soon after the end of the release, as expected. Considering all the above remarks we conclude that the examined RANS models are capable of predicting well both the release (turbulent) and the diffusion (laminar) phase.

Figure 13 presents the concentration time series for the LES approaches (Dynamic LES, RNG-LES and S-L LES). Sensor P2N3 has been excluded from these figures in order for the results to be more distinguishable and since it would not provide any further information. We observe that, unlike RANS models, all predicted time series exhibit oscillations, similarly to the experiment due to the resolved part of turbulence by the LES. The oscillations are particularly evident in P5N3 sensor due to its position above the release. The oscillations disappear during the diffusion phase for S-L 
and RNG-LES cases but continue to exist for Dynamic LES. This might be the reason for the greater level of mixing of Dynamic LES compared to the other LES predictions and the measurements as the diffusion phase progresses.

In contrast to RANS models, where the different models provide similar results, the different LES approaches give different predictions. At the top sensors (M3N5 and P5N3) Dynamic LES exhibits the best agreement with the experiment in the release phase. RNG-LES results are very close to the experiment in the release phase, with the exception of the first $1000 \mathrm{~s}$ of P5N3 sensor at which concentrations are over-predicted by approximately $28 \%$ and S-L LES generally under-predicts slightly the concentrations. The under-prediction increases as time progresses with the maximum discrepancy being equal to $7 \%$ at the end of the release. At medium sensors (M3N3 and M2N4) Dynamic LES exhibits again very good agreement with the experiment. S-L LES under-predicts slightly the concentrations at later times similar to the top sensors, whereas RNG-LES under-predicts the concentration at the initial stage (until 1500-2000 s) by up to $42 \%$. The results, however, are improved significantly after that period. At the lower sensors (M3N1, M2N2), Dynamic LES exhibits the least agreement with the experiment, under-predicting the concentrations up to $23 \%$ at M3N1 and up to $44 \%$ at M2N2.
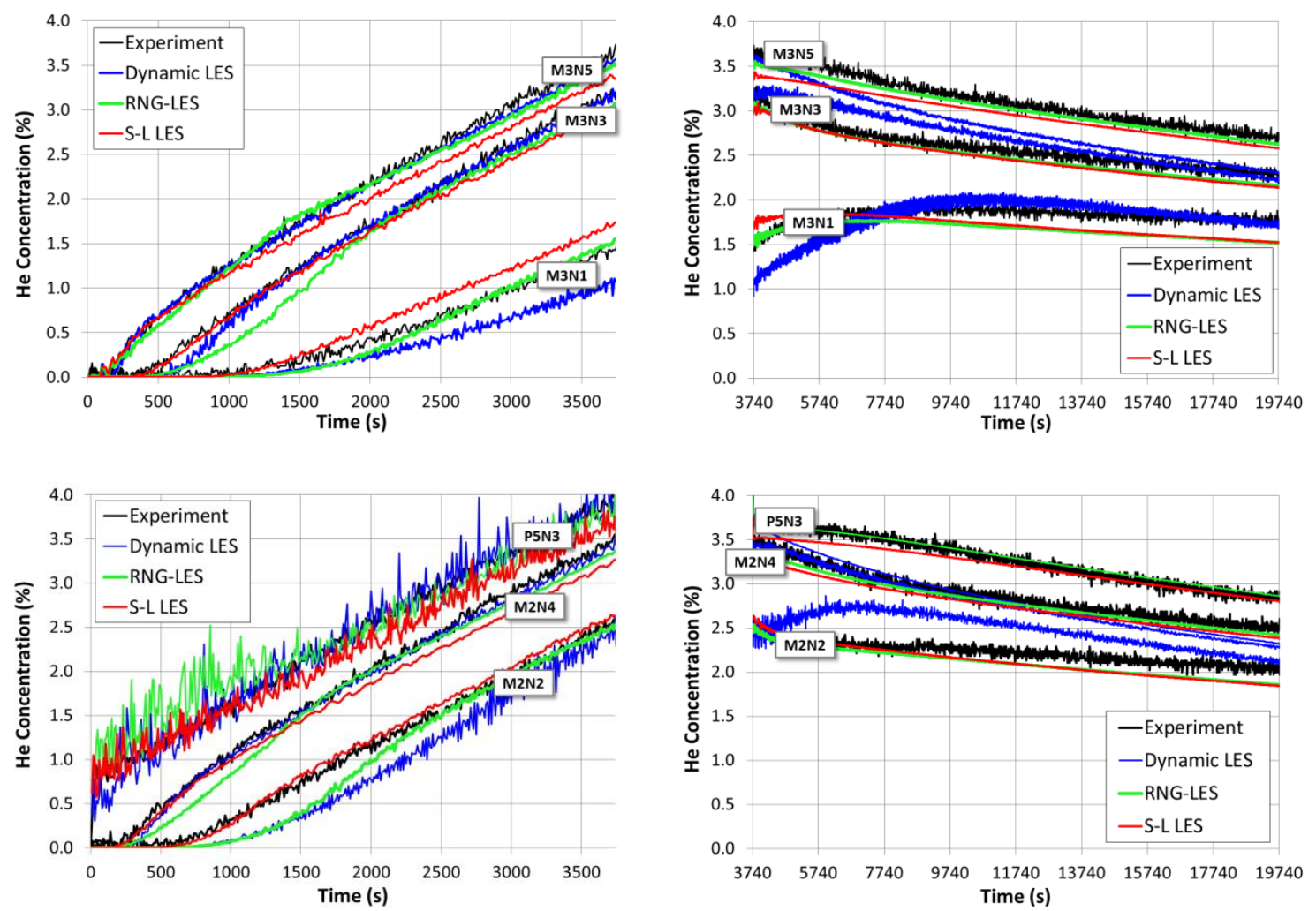

Figure 13. Helium volume concentration time series near the release point (top figures) and near the walls (bottom figures) for the LES and for the experiment during release (left figures) and diffusion (right figures) phase.

The predicted helium distribution inside the facility at the time when the release is stopped (3740 s) is shown in Figure 14. We observe that only minor differences exist between the two RANS models. The results of the different LES approaches are also similar. The more distinct stratification of the laminar model is evident. As far as the vertical concentration profiles are concerned, both RANS and LES approaches predict comparable results. All simulations predict uniform concentrations along the horizontal planes of a given height with the only exception the points which lie inside the release core. In diffusion phase (not shown here) this exception does not occur and a uniform mixture exists at all points of a given heights. 
The capability of the LES approaches to predict the instantaneous fluctuations of the flow field is evident in all LES contours. It is also interesting to note that LES seems to be able to predict the transition from laminar to turbulent flow. Helium distribution is initially stable forming a vertical column with sharp boundaries, while after a short distance from the release point the flow becomes unstable, eddies are formed and mixing is enhanced. The predicted distance at which the transition occurs is different in each simulation. Dynamic LES predicts the shortest distance, equal to $0.4 \mathrm{~m}$ from the release point, and RNG-LES the longest, equal to approximately $1.0 \mathrm{~m}$.
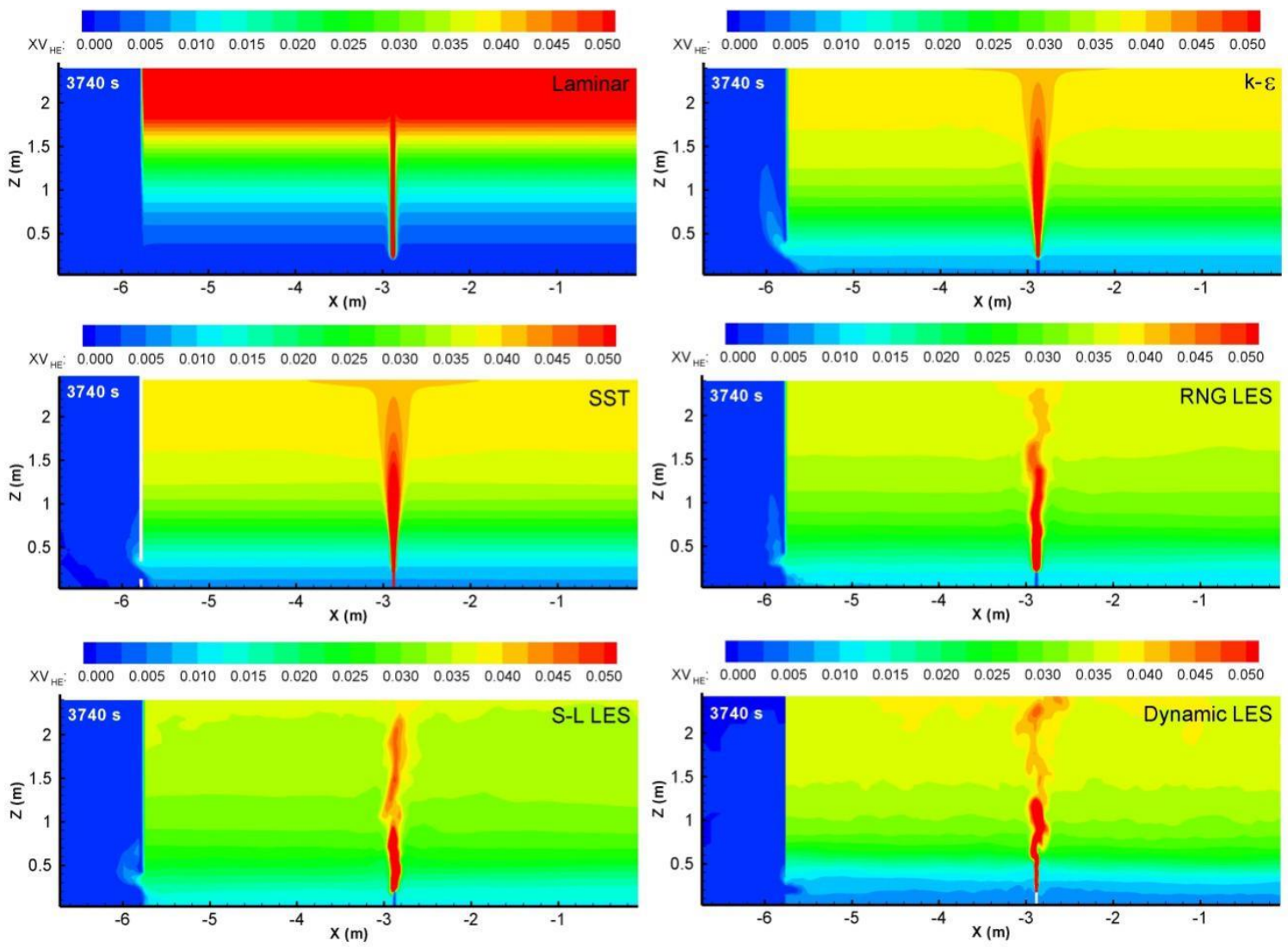

Figure 14. Helium volume concentration contours on y-injection plane at $3740 \mathrm{~s}$ predicted by the various turbulence modelling approaches.

To study and discuss about the produced by RANS and LES approaches flow field we present the velocity magnitude contours for $k-\varepsilon$ and RNG-LES at $2000 \mathrm{~s}$ and $3740 \mathrm{~s}$ in Figure 15. Due to buoyancy, the maximum velocity develops above the release point, at a distance of $0.4 \mathrm{~m}$ and it is approximately $1.0 \mathrm{~m} / \mathrm{s}$, i.e. two times higher than the release velocity. We observe that high velocities are observed only along the release direction. When helium reaches the ceiling and starts to spread laterally, significantly lower velocities occur.

In the same figure, stream-tracers are presented in order to visualize the flow field. Common characteristics exist between $k-\varepsilon$ and LES at both times. Recirculation-like zones exist at the top of the enclosure (stream-traces A1 and A2) which seems to make the mixture at this area more uniform (see also Figure 14). At the vent, the flow exits the enclosure from the top half and enters from the bottom one (stream-tracers $\mathrm{C} 1$ and $\mathrm{C} 2$ ) maintaining the pressure inside the enclosure approximately constant.

In k- $\varepsilon$ case paths are predicted which transfer helium from the upper part of the enclosure to the lower one and fresh air from the lower to the upper (stream-tracers B1 and B2). At 3740 s symmetry is observed between the stream-tracers A1-A2 and B1-B2, whereas at $2000 \mathrm{~s}$ a symmetric recirculation to A1 seems to be missing. In RNG-LES case, the stream-traces B1 and B2 indicate 
paths, which connect areas at low and medium heights with areas at top heights. Finally, eddies that are predicted by LES are apparent in stream-tracers D1.
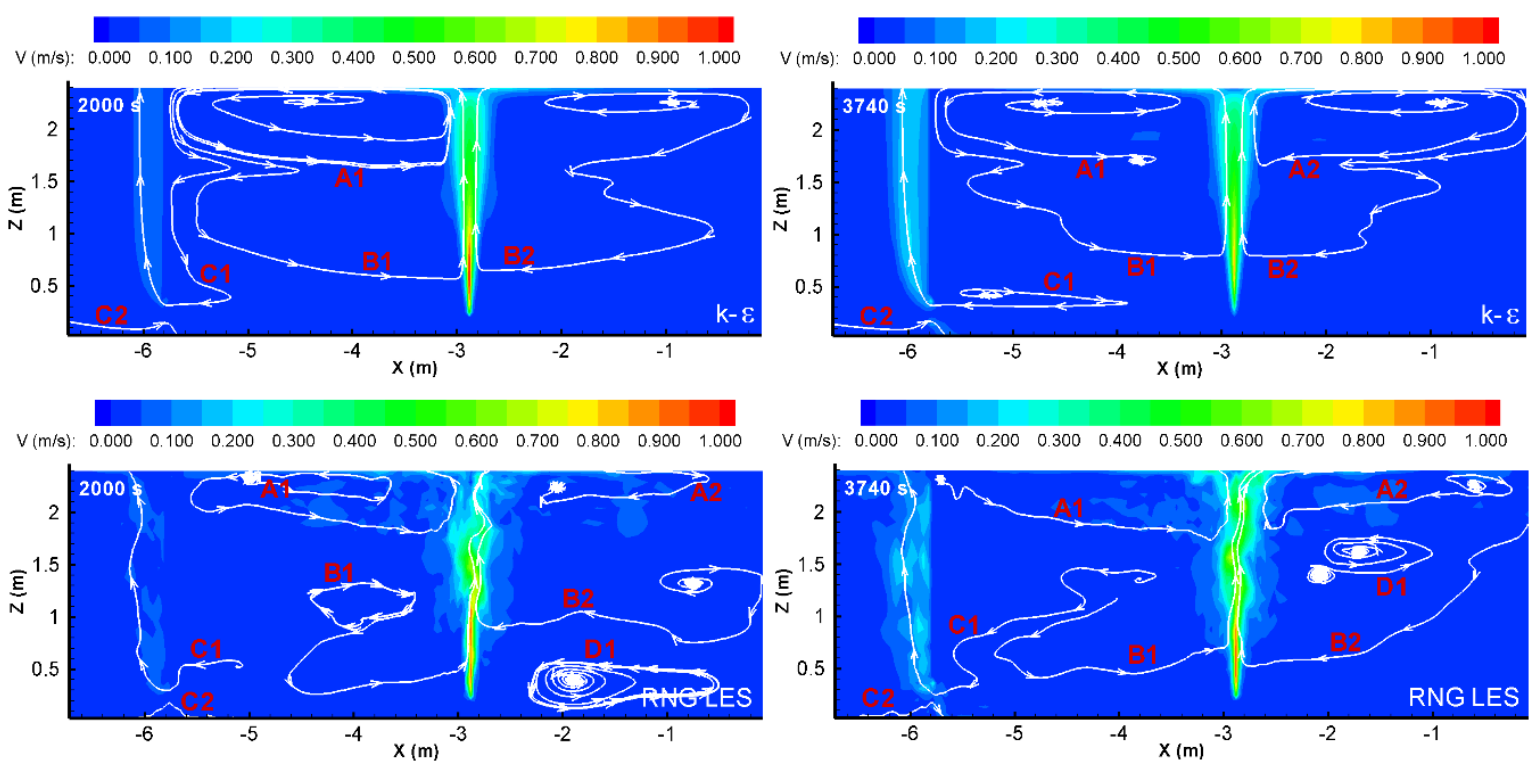

Figure 15. Predicted velocity magnitude contours by the $k-\varepsilon$ model (top) and RNG-LES (bottom) at $2000 \mathrm{~s}$ (left) and $3740 \mathrm{~s}$ (right). Characteristic stream-tracers are also shown.

In terms of safety, we observe in Figure 14 that concentration levels within hydrogen flammable limits $(4-75 \% \mathrm{v} / \mathrm{v})$ are met mainly in the jet core. This behaviour is reproduced by both RANS and LES with the $\mathrm{k}-\varepsilon$ and SST model to be the most conservative over-predicting the concentration near the ceiling. All the above indicate that leaks at such low rates in similar geometries generate concentration distributions where the flammable range occurs only/mainly in a limited region i.e. inside the jet.

For further model evaluation, the SPMs discussed in Section Statistical Performance Measures and Quantitative Assessment Criteria were used. Since no steady state is achieved the statistical analysis was performed for the helium concentration at $3740 \mathrm{~s}$ (end of release) over all sensors and is presented in Table 4. Moreover, the SPMs over the entire time series during the release phase and during the diffusion phase over the data from all sensors were derived using a time step of $10 \mathrm{~s}$ and are presented in Table 5 and Table 6, respectively. For the estimation of these SPMs, a moving averaging filter was applied to the time series in order to smooth out oscillations in experimental and LES results. In that way, the estimation of SPMs is more reliable.

Table 4. Model performance measures at $3740 \mathrm{~s}$ (sorted by minimum MG).

\begin{tabular}{cccccc}
\hline SPM & MG & VG & FB & NMSE & FAC1.2 (\%) \\
\hline Perfect model & $\mathbf{1}$ & $\mathbf{1}$ & $\mathbf{0}$ & $\mathbf{0}$ & $\mathbf{1 0 0}$ \\
RNG-LES & 1.03 & 1.00 & 0.04 & 0.003 & 98 \\
$k-\varepsilon$ & 1.04 & 1.01 & 0.01 & 0.004 & 89 \\
S-L LES & 1.04 & 1.01 & 0.06 & 0.008 & 94 \\
SST & 1.04 & 1.01 & 0.01 & 0.005 & 84 \\
Dynamic S-L LES & 1.12 & 1.24 & 0.04 & 0.005 & 89 \\
\hline
\end{tabular}


Table 5. Model performance measures over the entire dataset for the release phase (sorted by minimum MG).

\begin{tabular}{cccccc}
\hline SPM & MG & VG & FB & NMSE & FAC1.2 (\%) \\
\hline S-L LES & 1.14 & 1.37 & 0.06 & 0.010 & 88 \\
RNG-LES & 1.23 & 1.76 & 0.03 & 0.008 & 77 \\
SST & 1.24 & 1.71 & 0.01 & 0.009 & 76 \\
Dynamic S-L LES & 1.26 & 1.64 & 0.04 & 0.006 & 80 \\
$k-\varepsilon$ & 1.31 & 1.90 & 0.01 & 0.007 & 74 \\
Laminar & 2.07 & 85.5 & -0.34 & 0.81 & 6 \\
\hline
\end{tabular}

Table 6. Model performance measures over the entire dataset for the diffusion phase (sorted by best MG).

\begin{tabular}{cccccc}
\hline SPM & MG & VG & FB & NMSE & FAC1.2 (\%) \\
\hline SST & 1.02 & 1.01 & 0.00 & 0.003 & 94 \\
$k-\varepsilon$ & 1.03 & 1.01 & 0.02 & 0.003 & 95 \\
RNG-LES & 1.05 & 1.01 & 0.04 & 0.002 & 98 \\
S-L LES & 1.06 & 1.01 & 0.06 & 0.005 & 98 \\
Laminar & 0.95 & 1.15 & -0.15 & 0.12 & 43 \\
Dynamic S-L LES & 1.11 & 1.03 & 0.10 & 0.022 & 78 \\
\hline
\end{tabular}

For a systematic evaluation, a plot of MG versus VG for the concentration at $3740 \mathrm{~s}$ over all sensors and for the concentration over the release and diffusion phase for all sensors is used and presented in Figure 16. This type of plot shows also a parabola which represents the "minimum VG" curve, without any unsystematic errors, for a given MG [43]. All points should lie either on the parabola or inside. A perfect model would be the one that would be located on the parabola vertex $(1,1)$. The points that lie on the left hand side of the parabola show a tendency to over-predict, while the opposite shows a tendency to under-predict. 

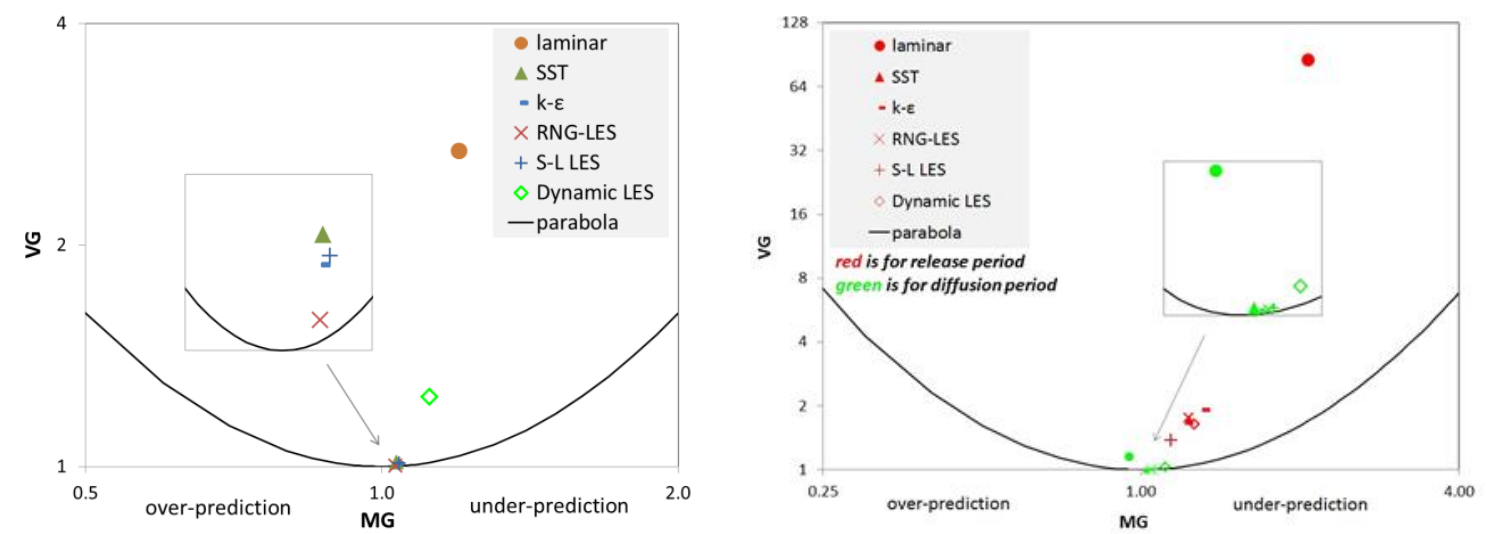

Figure 16. Geometric mean bias (MG) versus geometric mean variance (VG) for helium concentration at $3740 \mathrm{~s}$ (left) and during the release and diffusion phase (right) for all sensors.

Based on the statistical analysis the best agreement with the experiment at the end of the release is achieved by the RNG-LES and next with slight differences comes k- $\varepsilon$, S-L LES and SST. Dynamic LES exhibits the least good performance among the different turbulence approaches mainly due to the under-prediction at the low sensors. However, Dynamic LES has a relative high FAC1.2 measure, equal to $89 \%$ which means that $89 \%$ of all Dynamic LES predictions have an error of less than $20 \%$. The same FAC1.2 is achieved by $k-\varepsilon$ model, whereas RNG-LES has the highest FAC1.2, equal to $98 \%$. Laminar model has the worst measures overall, as expected.

In the release phase, S-L LES achieves the best agreement with the experiment and RNG-LES, SST, Dynamic LES and $k-\varepsilon$ follows. In the diffusion phase, SST, $k-\varepsilon$, RNG-LES and S-L LES have measures close to the ideal and Dynamic LES follows with worse measures due to the enhanced mixing that it predicts (Figure 13). The laminar model performs poorly in both the release and diffusion phase. It is expected that the poor performance of the laminar model in the diffusion phase is mainly due to the poor performance of the model in the release phase which produces inaccurate initial conditions for the diffusion phase. Finally, we observe that according to MG, there is a small tendency by all models (except the laminar one in the diffusion phase) to overall under-predict the concentrations.

Although the LES approaches are in very good agreement with the experiment, they have considerably higher computational cost compared to the RANS models. The simulation run time of S-L LES and RNG-LES was almost 20 and 27 times slower, respectively, compared to $k-\varepsilon$ simulation with the same grid and in the same processor. The reason for the higher computational time of the LES simulations is the smaller time step that is generally required in LES type models and the larger number of iterations that were required for convergence in each time step.

\section{Conclusions}

This study focuses on the proper modelling of flammable buoyant gas release and dispersion inside a closed facility. It demonstrates how to properly follow BPG for CFD simulations and assesses CFD models/tools for predicting helium/hydrogen distribution inside an enclosure resulting from a low-Reynolds number leak. Several turbulence models along with the laminar model using three CFD codes were examined to evaluate their performance and to characterize the flow in such applications. Through the sensitivity studies that were conducted based on BPG [13] interesting remarks are drawn for the domain and the grid design. The findings of this study would assist the design of safer hydrogen infrastructure by indicating appropriate modelling strategies for reliable safety assessments and can be summarized in the following points: 
- At such low-Reynolds number leaks $(R e=115)$ of buoyant gases, e.g. hydrogen, the flow becomes turbulent at some point downwind the release despite the laminar flow at the pipe exit due to buoyant acceleration. Only when the release is stopped the gas decelerates and the flow becomes laminar.

- $\quad$ RANS and LES predictions demonstrate good predictive capabilities, while the laminar model performs poorly and fails to reproduce the gas distribution inside the facility predicting a more distinct stratification.

- In the diffusion phase (after the end of the release), all turbulence approaches achieve very good agreement with the experiment. Despite more uniform mixture prediction by the Dynamic LES at diffusion, the release phase was reproduced in close agreement with experiment. The laminar can also give consistent results in the diffusion phase, since the flow is laminar, provided that accurate initial flow field after the end of the release is used.

- For engineering computations, RANS models seem to be a good compromise between accuracy and computational cost.

- Tetrahedral mesh produces high numerical diffusion affecting significantly the results of the laminar model. This effect can be smaller but not negligible when RANS turbulence models are used.

- Narrower acceptable ranges for the assessment criteria of the SPMs $(-0.18<\mathrm{FB}<0.23$, NMSE $<0.05, \quad 0.83<\mathrm{MG}<1.25$ and $\mathrm{VG}<1.05, \quad \mathrm{FAC} 1.2)$ are suggested for dispersion in indoor/closed environments compared to those that are usually employed for outdoor configurations.

- Helium is an excellent surrogate of hydrogen under the same volumetric release rate. In terms of safety, leaks at low release rates in similar geometries generate concentration distributions where the flammable range occurs only/mainly in a limited region i.e. inside the jet.

\section{Acknowledgements}

The research leading to these results is financially supported by the SUSANA project, which has received funding from the European Union's Seventh Framework Programme (FP7/2007-2013) for the Fuel Cells and Hydrogen Joint Technology Initiative under grant agreement n ${ }^{\circ}$ FCH-JU-325386.

The authors would like also to thank the French Atomic Energy Commission (CEA) for providing the experimental data.

\section{References}

1. Venetsanos, A.G.; Baraldi, D.; Adams, P.; Heggem, P.S.; Wilkening, H. CFD modelling of hydrogen release, dispersion and combustion for automotive scenarios. J. Loss Prev. Process Ind. 2008, 21, 162-184.

2. Efthimiou, G.C.; Andronopoulos, S.; Tavares, R.; Bartzis, J.G. CFD-RANS prediction of the dispersion of a hazardous airborne material released during a real accident in an industrial environment. J. Loss Prev. Process Ind. 2017, 46, 23-36.

3. Molkov, V.; Shentsov, V. Numerical and physical requirements to simulation of gas release and dispersion in an enclosure with one vent. Int. J. Hydrogen Energy 2014, 39, 13328-13345.

4. Shi, J.; Chang, B.; Khan, F.; Chang, Y.; Zhu, Y.; Chen, G.; Zhang, C. Stochastic explosion risk analysis of hydrogen production facilities. Int. J. Hydrogen Energy 2020, 45, 13535-13550, https://doi.org/10.1016/j.ijhydene.2020.03.040.

657 5. Skjold, T.; Siccama, D.; Hisken, H.; Brambilla, A.; Middha, P.; Groth, K.M.; LaFleur, A.C. 3D risk 
management for hydrogen installations. Int. J. Hydrogen Energy 2017, 42, 7721-7730, https://doi.org/10.1016/j.ijhydene.2016.07.006.

660 6. Giannissi, S.G.; Tolias, I.C.; Venetsanos, A.G. Mitigation of buoyant gas releases in single-vented enclosure exposed to wind: Removing the disrupting wind effect. Int. J. Hydrogen Energy 2016, 41, 40604071, https://doi.org/10.1016/j.ijhydene.2015.12.142.

7. Baraldi, D.; Melideo, D.; Kotchourko, A.; Ren, K.; Yanez, J.; Jedicke, O.; Giannissi, S.G.; Tolias, I.C.; Venetsanos, A.G.; Keenan, J.; et al. Development of a Model Evaluation Protocol for CFD Analysis of Hydrogen Safety Issues - The SUSANA Project. Int. J. Hydrogen Energy 2017, 42, 7633-7643.

8. Gallego, E.; Migoya, E.; Martín-Valdepeñas, J.M.; Crespo, A.; García, J.; Venetsanos, A.; Papanikolaou, E.; Kumar, S.; Studer, E.; Dagba, Y.; et al. An intercomparison exercise on the capabilities of CFD models to predict distribution and mixing of $\mathrm{H} 2$ in a closed vessel. Int. J. Hydrogen Energy 2007, 32, 2235-2245, https://doi.org/10.1016/j.ijhydene.2007.04.009.

9. Papanikolaou, E.A.; Venetsanos, A.G.; Heitsch, M.; Baraldi, D.; Huser, A.; Pujol, J.; Garcia, J.; Markatos,

10. Venetsanos, A.G.; Papanikolaou, E.; Hansen, O.R.; Middha, P.; Garcia, J.; Heitsch, M.; Baraldi, D.;

11. Giannissi, S.; Shentsov, V.; Melideo, D.; Cariteau, B.; Baraldi, D.; Venetsanos, A.G.; Molkov, V. CFD benchmark on hydrogen release and dispersion in confined, naturally ventilated space with one vent. Int. J. Hydrogen Energy 2015, 40, 2415-2429, https://doi.org/10.1016/j.ijhydene.2014.12.013.

12. Bernard-Michel, G.; Saikali, E.; Sergent, A.; Tenaud, C. Comparisons of experimental measurements and large eddy simulations for a helium release in a two vents enclosure. Int. J. Hydrogen Energy 2018, https://doi.org/10.1016/J.IJHYDENE.2018.07.120.

13. Tolias, I.C.; Giannissi, S.G.; Venetsanos, A.G.; Keenan, J.; Shentsov, V.; Makarov, D.; Coldrick, S.; Kotchourko, A.; Ren, K.; Jedicke, O.; et al. Best practice guidelines in numerical simulations and CFD benchmarking for hydrogen safety applications. Int. J. Hydrogen Energy 2018, https://doi.org/10.1016/J.IJHYDENE.2018.06.005.

687 14. Hall, R.C. Evaluation of modelling uncertainty. CFD modelling of near-field atmospheric dispersion.

689 15. Wilcox, D.C. Turbulence Modeling for CFD; 3rd ed.; DCW Industries, Inc., La Canada, California, 2006; 690 ISBN 0963605100.

691 16. Pope, S.B. Turbulent Flows; Cambridge University Press, 2000; ISBN 0521598869.

692 17. Launder, B.E.; Sandham, N.D. Closure Strategies for Turbulent and Transitional Flows; Launder, B.E., Ed.; 
694 18. Sagaut, P. Large eddy simulation for incompressible flows: An introduction; Springer, Ed.; 3rd ed.; 2006; ISBN 695 978-3- 540-26403-3.

696 19. Launder, B.E.; Spalding, D.B. The numerical computation of turbulent flow. J. Comput Methods Appl Mech Eng 1974, 3(2), 269-289.

20. Argyropoulos, C.D.; Markatos, N.C. Recent advances on the numerical modelling of turbulent flows. Appl. Math. Model. 2015, 39, 693-732, https://doi.org/10.1016/j.apm.2014.07.001.

21. Gupta, S.; Brinster, J.; Studer, E.; Tkatschenko, I. Hydrogen related risks within a private garage: Concentration measurements in a realistic full scale experimental facility. Int. J. Hydrogen Energy 2009, 34, 5902-5911, https://doi.org/10.1016/j.ijhydene.2009.03.026.

22. He, J.; Kokgil, E.; Wang, L. (Leon); Ng, H.D. Assessment of similarity relations using helium for prediction of hydrogen dispersion and safety in an enclosure. Int. J. Hydrogen Energy 2016, 41, 1538815398, https://doi.org/10.1016/J.IJHYDENE.2016.07.033.

23. Prabhakar, A.; Agrawal, N.; Raghavan, V.; Das, S.K. Numerical modelling of isothermal release and distribution of helium and hydrogen gases inside the AIHMS cylindrical enclosure. Int. J. Hydrogen Energy 2017, 42, 15435-15447, https://doi.org/10.1016/J.IJHYDENE.2017.04.296.

24. Versteeg, H.; Malalasekera, W. An introduction to computational fluid dynamics: the finite volume method; 2007 ;

711 25. Ungate, C.; Harleman, D.; Jirka, G. Stability and mixing of submerged turbulent jets at low Reynolds 712 numbers. Energy Lab. Rep. 1975.

713 26. Landa, P.S.; McClintock, P.V.E. Development of turbulence in subsonic submerged jets. Phys. Rep. 2004, 397, 1-62, https://doi.org/10.1016/j.physrep.2004.03.004.

27. Schefer, R.W.; Houf, W.G.; Williams, T.C. Investigation of small-scale unintended releases of hydrogen: buoyancy effects. Int. J. Hydrogen Energy 2008, 33, 4702-4712.

28. Strelets, M. Detached Eddy Simulation of Massively Separated Flows. In Proceedings of the AIAA

29. Bartzis, J.G. ADREA-HF: a three-dimensional finite volume code for vapour cloud dispersion in complex terrain. Rep. EUR 13580 EN 1991.

31. Menter, F.R. Two-equation eddy-viscosity turbulence models for engineeringapplications. AIAA-J. $1994,32$. 
33. F.R., M.; R.B., L.; S.R., L.; Y.B., S.; Huang P.G., V.S. A correlation based transition model using local variables Part 1: model formulation. In Proceedings of the ASME-GT2004-53452. Vienna, Austria: ASME TURBO EXPO; 2004.

34. Langtry, R.B.; Menter, F.R. Transition modeling for general CFDapplications in aeronautics. AIAA Pap. 2005-522 2005.

35. Koutsourakis, N.; Venetsanos, A.G.; Bartzis, J.G. LES modelling of hydrogen release and accumulation within a non-ventilated ambient pressure garage using the ADREA-HF CFD code. Int. J. Hydrogen Energy 2012, 37, 17426-17435.

36. Yakhot, V.; Orszag, S. Renormalization group analysis of turbulence. I. Basic theory. J. Sci. Comput. 1986, $1,3-51$.

37. Saikali, E.; Bernard-Michel, G.; Sergent, A.; Tenaud, C.; Salem, R. Highly resolved large eddy simulations of a binary mixture flow in a cavity with two vents: Influence of the computational domain. Int. J. Hydrogen Energy 2019, 44, 8856-8873, https://doi.org/10.1016/j.ijhydene.2018.08.108.

38. Gullbrand, J. Grid-independent large-eddy simulation in turbulent channel using three-dimensional explicit filtering. Cent. Turbul. Res. Annu. Res. Briefs 2002.

39. Gant, S.E. Reliability issues of LES-related approaches in an industrial context. Flow, Turbul. Combust. 2010, 84, 325-335.

40. Geurts, B.J. Interacting errors in large-eddy simulation: a review of recent developments. J. Turbul. 2006, 7, 1-16.

41. Hanna, S.R. Confidence limits for air quality model evaluations, as estimated by bootstrap and jackknife resampling methods. Atmos. Environ. 1989, 23, 1385-1398.

42. Schatzmann, M.; Olesen, H.; Franke, J. Model evaluation case studies: approach and results; COST Action 732 Quality assurance and improvement of microscale meteorological models, ISBN: 3-00-018312-4. University of Hamburg., 2010; ISBN 3-00-018312-4.

43. Chang, J.; Hanna, S. Air quality model performance evaluation. Meteorol. Atmos. Phys. 2004, 87, $167-196$.

44. Barth, Ti.; Jespersen, D. The design and application of upwind schemes on unstructured meshes. In Proceedings of the 27th Aerospace Sciences Meeting; American Institute of Aeronautics and Astronautics: Reston, Virigina, 2013. 